\title{
Longitudinal relationships between hearing aid use and cognitive function in older Americans
}

DOI:

10.1111/jgs. 15363

\section{Document Version}

Accepted author manuscript

Link to publication record in Manchester Research Explorer

\section{Citation for published version (APA):}

Maharani, A., Dawes, P., Nazroo, J. Y., Tampubolon, G., Pendleton, N., \& Leroi, I. (2018). Longitudinal relationships between hearing aid use and cognitive function in older Americans. Journal of the American Geriatrics Society, 66(6), 1130-1136. https://doi.org/10.1111/jgs.15363

\section{Published in:}

Journal of the American Geriatrics Society

\section{Citing this paper}

Please note that where the full-text provided on Manchester Research Explorer is the Author Accepted Manuscript or Proof version this may differ from the final Published version. If citing, it is advised that you check and use the publisher's definitive version.

\section{General rights}

Copyright and moral rights for the publications made accessible in the Research Explorer are retained by the authors and/or other copyright owners and it is a condition of accessing publications that users recognise and abide by the legal requirements associated with these rights.

\section{Takedown policy}

If you believe that this document breaches copyright please refer to the University of Manchester's Takedown Procedures [http://man.ac.uk/04Y6Bo] or contact uml.scholarlycommunications@manchester.ac.uk providing relevant details, so we can investigate your claim.

\section{OPEN ACCESS}




\section{Journal of the}

American Geriatrics Society

\section{Longitudinal relationships between hearing aid use and cognitive function in older Americans}

\begin{tabular}{|r|l|}
\hline Journal: & Journal of the American Geriatrics Society \\
\hline Manuscript ID & JAGS-0091-CI-Jan-18.R1 \\
\hline Watey - Manuscript type: & Clinical Investigation \\
\hline Complete List of Authors: & $\begin{array}{l}\text { Maharani, Asri; University of Manchester, Division of Neuroscience and } \\
\text { Experimental Psychology } \\
\text { Dawes, Piers; University of Manchester, Division of Human Communication, } \\
\text { Development \& Hearing } \\
\text { Nazroo, James; University of Manchester, Sociology and Cathie Marsh } \\
\text { Institute for Social Research } \\
\text { Tampubolon, Gindo; University of Manchester, Sociology and Cathie Marsh } \\
\text { Institute for Social Research } \\
\text { Pendleton, Neil; The University of Manchester, Division of Neuroscience } \\
\text { and Experimental Psychology, School of Biological Sciences }\end{array}$ \\
\hline Key Words: & \begin{tabular}{l} 
hearing aid use, cognition, longitudinal analysis \\
\hline
\end{tabular} \\
\hline
\end{tabular}


1 Title : Longitudinal relationships between hearing aid use and cognitive function in older

2 Americans

3 Short running title : Hearing aid use and cognitive function in older adults

4 Author : Asri Maharani, $\mathrm{PhD},{ }^{1}$ Piers Dawes, $\mathrm{PhD},{ }^{2}$ James Nazroo, Professor, ${ }^{3}$ Gindo

5 Tampubolon, $\mathrm{PhD},{ }^{3}$ and Neil Pendleton, Professor, ${ }^{1}$ on behalf of the Sense-Cog WP1

6 group

7 Corresponding author: Asri Maharani

8 Address: Humanities Bridgeford Street Building G21, Oxford Road, Manchester M13 9PL,

9 United Kingdom

10 Telephone: +4416157025

11 Email address: asri.maharani@manchester.ac.uk

\section{Author affiliation and qualification:}

131 Division of Neuroscience and Experimental Psychology, School of Biological Sciences,

14 Faculty of Biology, Medicine and Health, University of Manchester, Manchester Academic

15 Health Science Centre, Manchester M13 9PL, United Kingdom

162 Division of Human Communication, Development \& Hearing, University of Manchester,

17 Oxford Road, Manchester M13 9PL, United Kingdom

183 Sociology and Cathie Marsh Institute for Social Research, University of Manchester

19 Humanities Bridgeford Street Building, Oxford Road, Manchester M13 9PL, United

20 Kingdom 
22 We certify that this work is novel of recent novel clinical research. This manuscript is

23 important for the literature as it showed for the first time that cognitive decline at different

24 rate before and after the beginning of hearing aid use which holds an important public health

25 implication to improve cognitive health and prevent dementia among older people.

\section{Conflict of interest:}

27 The authors have no financial or any other kind of personal conflicts with this paper.

\section{Authors Contributions:}

29 AM, GT, JN, PD and NP made substantial contributions to the study design. AM analysed 30 the data. GT, JN, PD and NP contributed to the statistical design of the study. AM, GT, JN,

31 PD and NP contributed to the interpretation of the data and wrote each draft of the

32 manuscript. All authors critically reviewed and contributed significantly to the intellectual

33 content of the manuscript. AM had full access to all the data in the study and all authors had

34 final responsibility for the decision to submit for publication.

\section{Acknowledgement:}

36 The Sense-Cog WP1 group are Geir Bertelsen ${ }^{1,2}$, Suzanne $\operatorname{Cosh}^{3}$, Audrey Cougnard-

37 Grégoire $^{3}$, Cécile Delcourt ${ }^{3}$, Fofi Constantinidou ${ }^{4}$, Catherine Helmer ${ }^{3}$, M. Arfan Ikram ${ }^{5,6}$,

38 Caroline CW Klaver ${ }^{5,7}$, Iracema Leroi ${ }^{8}$, Magda Meester-Smor ${ }^{5,7}$, Unal Mutlu ${ }^{5,7}$, Virginie

$39 \mathrm{Nael}^{3,9,10}$, Henrik Schirmer ${ }^{11}$, Henning Tiemeier ${ }^{5,12}$, Therese von Hanno ${ }^{13,14}$.

40 1: UiT The Arctic University of Norway, Department of Community Medicine, Faculty of

41 Health Sciences, N-9037 Tromsø, Norway

42 2: University Hospital of North Norway, Department of Ophthalmology, N-9038 Tromsø,

43 Norway 
3: Univ. Bordeaux, Inserm, Bordeaux Population Health Research Center, team LEHA, UMR 1219, F-33000 Bordeaux, France

4: University of Cyprus, Department of Psychology \& Center for Applied Neuroscience, Nicosia, Cyprus

5: Erasmus Medical Centre, Department of Epidemiology, Rotterdam, The Netherlands

6: Erasmus Medical Centre, Departments of Neurology and Radiology, Rotterdam, The Netherlands

7: Erasmus Medical Centre, Department of Ophthalmology, Rotterdam, The Netherlands

8: University of Manchester, Division of Neuroscience and Experimental Psychology, School of Biological Sciences, Manchester, UK

9: Sorbonne University, UMPC University of Paris 06, INSERM, CNRS, Vision Institute, F75012 Paris, France

10: R\&D Life and Vision Science, Essilor International, F-75012 Paris, France 11: UiT-The Arctic University of Norway, Department of Clinical Medicine, Cardiovascular research Group-UNN, N-9037 Tromsø, Norway

12: Erasmus Medical Centre, Department of Psychiatry, Rotterdam, The Netherlands 13: UiT-The Arctic University of Norway, Department of Clinical Medicine, Faculty of Health Sciences, N-9037 Tromsø, Norway

14: Nordland Hospital, Department of Ophthalmology, N-8092 Bodø, Norway

\section{Funding source:}

45 This work was supported by SENSE-Cog project. This project has received funding from the 46 European Union's Horizon 2020 research and innovation programme under grant agreement $47 \quad$ No 668648.

48 Abstract word counts: 195 words 
49 Main document word counts: 2,999 words

50 Number of tables: 2 tables

51 Number of figures: 2 figures

52 


\section{Abstract}

54 Objective: To test whether hearing aid use alters cognitive trajectories in older adults.

55 Design, setting, and participants: Data were drawn from the Health and Retirement Study 56 (HRS), a US population-based longitudinal cohort study with cognitive performance 57 measured repeatedly every 2 years over 18 years (1996-2014). This study included 1,586 58 adults aged 50 and older who who took part in a minimum of three waves of the HRS and 59 who used hearing aids for the first time between Wave 4 and Wave 11.

60 Masurements: Cognitive outcomes were based on episodic memory scores determined by

61 the sum of immediate and delayed recall of 10 words.

62 Results: Hearing aid use was positively associated with episodic memory scores $(\beta=1.24$, $63 p<0.001)$. The decline in episodic memory scores was slower after $(\beta=-0.02, p<0.001)$ than 64 before using hearing aids $(\beta=-0.1, \quad p<0.001)$. These results were robust to adjustment for 65 multiple confounders and and to attrition as accounted for with joint model.

66 Conclusions: Hearing aids may have a mitigating impact on trajectories of cognitive decline 67 in later life. Providing hearing aids or other rehabilitative services for hearing impairment 68 much earlier in the course of hearing impairment may stem the worldwide rise of dementia.

69 Key words: Hearing aid use, cognition, longitudinal analysis 


\section{Introduction}

74 Neurodegenerative dementias such as Alzheimer disease are a major health problem in the

75 worldwide aging population. The number of people living with dementia is projected to

76 increase by $57 \%$ in the next two decades, from 46 million in 2015 to 72 million in 2050 . $^{1,2}$

77 This rising global prevalence, combined with the lack of effective curative treatment, has

78 rendered the prevention of dementia a public health concern.

79 A recent study by Livingston et al. (2017) showed that intervention on risk factors not

80 including hypertension might prevent $35 \%$ of dementia cases ${ }^{3}$ and that the strongest midlife

81 risk factor for dementia is hearing impairment. It showed that approximately $9 \%$ of dementia

82 cases are attributable to hearing loss in midlife. Our previous study, using three longitudinal

83 surveys on ageing health, showed that individuals with hearing and visual impairments had

84 lower episodic memory scores and a more adverse trajectory of decline in memory scores

85 with age than those with no impairment. ${ }^{4}$ The relationship between of hearing impairment

86 and lower cognitive ability in later life has also been reported by numerous cross-sectional ${ }^{5-7}$

87 and longitudinal studies. ${ }^{8-10}$ As hearing impairment is prevalent, alleviating it might delay the

88 point that older adults cross the critical threshold of impairment into dementia.

89 Hearing impairment as a risk factor for dementia is not only greater than other individual

90 midlife risks but is also relevant to many individuals because of its relatively high prevalence

91 in middle and old age. At least $10 \%$ of individuals aged 40 to 69 years show some degree of

92 measurable hearing impairment ${ }^{11}$ and that this proportion increases with age. The prevalence

93 of hearing impairment increases to $30 \%$ of individuals over the age of 65 , and between $70 \%$

94 and $90 \%$ individuals over the age of 85 experience some hearing loss. ${ }^{12,13}$ Although hearing

95 impairment is highly prevalent, it remains largely under treated. ${ }^{14}$ Only 1 in 7 adults aged 50+ 
96 with hearing impairment use hearing aids, and this figure declines to fewer than 1 in 20 for

97 working-aged adults (50-59 years old). ${ }^{12}$

98 The effect of hearing aid interventions on cognitive function remains poorly understood.

99 Cross-sectional studies from the $\mathrm{US}^{5}$ and the $\mathrm{UK}^{15}$ have reported that hearing aid use is 100 associated with better cognitive scores. In contrast, a study using a cross-sectional cohort of

101 the Baltimore Longitudinal Study of Aging found no significant relationship between hearing 102 aid use and cognitive ability. ${ }^{16}$ The insignificant effect of hearing aid use on cognitive 103 function was also shown in several small longitudinal studies of short duration. ${ }^{8-10,17,18}$

104 We used an 18-year follow-up of the Health and Retirement Study cohort to assess the 105 consequences of hearing aid use on long-term age-related decline in episodic memory. Using 106 a self-reported measure of hearing aid use, the association between hearing impairment and 107 cognitive trajectories over 18 years was investigated in a community-based cohort of older 108 adults, and the trajectories of the individuals before using hearing aids were compared with 109 those after beginning to use hearing aids.

\section{Methods}

111 This study forms part of the SENSE-Cog multi-phase research programme, funded by the 112 European Union Horizon 2020 programme. SENSE-Cog aims to promote mental well-being 113 in older adults with sensory and cognitive impairments (http://www.sense-cog.eu/). The first 114 work package of this project aims to better understand the links among sensory, cognitive and 115 mental ill-health in older Europeans. 
119 Our empirical analysis used the Health and Retirement Study (HRS) Waves 3 (1996-97) - 12

120 (2014-15). The HRS is an ongoing biennial investigation of US adults aged 50 years and

121 older that started in 1992. Sponsored by the National Institute of Aging and performed by the

122 Institute for Social Research at the University of Michigan, the HRS provides information on

123 demographic, socio-economic factors, and health.

124 We used Wave 3 and later of the HRS as the episodic memory scores using 10 words were 125 first available in the third wave. In our study, we restricted the sample to respondents age 50

126 years and older who responded to at least three waves of HRS, had no dementia in the

127 baseline, and used hearing aids for the first time between Waves 4 and 11. This gave a 128 sample of 2,040 individuals with the selection procedure as illustrated in Figure 1. We 129 describe the characteristics of the HRS core sample Waves 3-12, HRS core sample with at 130 least 3 observations and the final sample in Appendix 1. It shows that the average of age and 131 episodic memory scores of the core sample Waves 3-12 and final sample are similar.

132 Measures

133 The measures of cognitive ability in the HRS are the outcomes of simple tests, e.g. immediate 134 and delayed word recall (episodic memory), serial 7's test, backwards count starting from 20, 135 and date naming. In our analysis, we focused on one specific cognitive domain available in 136 all HRS waves used in this study: episodic memory. We were particularly interested in 137 episodic memory scores as they are more age-sensitive than other cognitive measures, ${ }^{19}$ do 138 not suffer from floor or ceiling effects, ${ }^{20}$ have a common mechanism with cognitive control 139 variables $^{14}$ and have a strong association with dementia. After allowing for established risk 140 factors for dementia, the odds ratio for dementia among members of the most advantaged 
141 trajectory of episodic memory was more than five times lower than the reference

142 (disadvantaged) trajectory. ${ }^{21}$ In the HRS memory test, the interviewer read a list of 10 simple

143 nouns (e.g. book, child, hotel, etc.) once and the participants were asked to repeat those nouns

144 on two occasions: immediately after the words were read out (immediate recall) and after a

145 short interval (delayed recall). We calculated the episodic memory score as the sum of the

146 number of target words recalled at the immediate and the delayed recall phase (score ranging

147 from 0 to 20$){ }^{20}$

148 The timing of using hearing aids for the first time was based on self-definition through the

149 question: 'Do you ever wear a hearing aid?'. This question was posed to all respondents.

150 Based on the first time that respondents answered 'yes' to that question, we constructed a

151 dummy variable for hearing aid use ( 1 for the wave the first time the respondents used

152 hearing aids and after, 0 for the wave before the respondents used hearing aids). In total,

1531,586 respondents used hearing aids for the first time during the fourteen-year period.

154 We included an extensive set of covariates as identified as risk factors for cognitive decline in

155 prior studies. ${ }^{22-25}$ Demographic covariates included age (in years) and sex (female as the

156 reference). Socio-economic covariates included education (less than high school, high school,

157 and college or higher), marital status (married or cohabiting, and not married) and wealth

158 (tertiles of income each wave). The lifestyle behaviour covariates included smoking, drinking

159 behaviour and physical activities. For smoking behaviour, respondents were classified as

160 non-smokers, past smokers and current smokers. We used the number of units per week to

161 measure drinking behaviour. Depressive symptoms were assessed with the 8-item Centre for

162 Epidemiological Studies Depression Scale. ${ }^{26}$ Lastly, the number of comorbidities present was

163 included as the sum of several chronic diseases: heart disease, high blood pressure, lung

164 diseases, diabetes, stroke and cancer. 
166 To model trajectories in episodic memory scores, we used hierarchical linear regression 167 analysis, which is designed to analyse longitudinal data. In this regression analysis, intra168 individual correlation is modelled using an individual specific random intercept and an 169 individual specific random slope. This analysis thus takes into account multiple observations 170 within individual and intra-individual correlation. In addition, it allows for adjustment of 171 potential confounding variables. We used a spline model with a knot at the beginning of 172 hearing aid use and assessed whether the slope before using hearing aid differed to the post173 hearing aid use slope. We included the hearing aid variable (coded as 1 after using hearing 174 aids and 0 prior to using hearing aids) and its interaction with the slope term (age) to test the 175 differences in cognitive trajectories before and after beginning to use hearing aids. The 176 associations between hearing aid use, age, age interaction with hearing aid use and episodic 177 memory scores were quantified in the first model. The demographic and socio-economic 178 determinants (age, gender, education, marital status, and wealth) and the variables 179 representing lifestyle behaviour, depression, and the number of chronic diseases present were 180 added in the final model.

\section{Sensitivity analysis}

183 For the first sensitivity analysis, we conducted two separated hierarchical linear regression 184 analyses with immediate and delayed word recall as the outcomes, while the second analysis 185 focused on attrition. The HRS, like other longitudinal studies on ageing is subject to attrition

186 in which respondents are prone to selective dropout due to death or poor health. ${ }^{27,28}$ Ignoring 187 those dropouts thus can result in bias in the analysis. We tested the sensitivity of our results 
188 to attrition by using a joint model. ${ }^{29}$ This resultant division into two parts, the growth curve 189 model and the survival model, allowed the random effects to influence both episodic memory 190 and attrition. Finally, we examined the role of gender in the association between hearing aid 191 use and cognitive function by conducting separate analyses for females and males. The 192 models were constructed using STATA 14 and Latent Gold 5.1.

\section{Results}

194 Table 1 shows the descriptive statistics of 2,040 HRS sample respondents who used hearing 195 aids for the first time between Waves 4 and 11 at the first wave observed. The episodic 196 memory score has a distribution close to the normal distribution with a sample mean of 10.4 197 and a standard deviation of 3.2. On average the respondents used hearing aids for the first 198 time at 63 years old. The respondents were mostly males (61\%) who had completed college 199 or higher $(45 \%)$ and were married $(81 \%)$. The bivariate regression model (see Table 1 , 200 second and third columns) shows that age, depression score, and number of comorbidities 201 have a negative and significant association with episodic memory scores. Being relatively 202 well educated, drinking alcohol and engaging regularly in physical activities are positively 203 associated with episodic memory scores.

204 The parameter estimates for the slope of episodic memory scores before and after beginning 205 to use hearing aids in an initial model are presented in Table 2, left pane. Episodic memory 206 declined significantly with the addition of age, but the rate of the decline was slower after 207 beginning to use hearing aids $(\beta=-0.03, p<0.001)$ than before $(\beta=-0.11, p<0.001)$. The 208 difference of the coefficient between those two slopes is $0.08(p<0.001)$. In this model, 209 hearing aid use was associated with higher memory scores $(\beta=2.13, p<0.001)$. The 210 association between hearing aid use and episodic memory scores remained significant when

211 we included the risk factors in the second model $(\beta=1.24, p<0.001)$. In this second model, 
212 slopes for the decline of episodic memory scores remained steeper before beginning hearing

213 aid use $(\beta=-0.1, p<0.001)$ than after $(\beta=-0.02, p<0.001)$.

214 In the second model, several potential confounders and socio-demographic characteristics

215 showed significant associations with episodic memory scores. Being female, having attained

216 a higher level of education, having a higher income, drinking alcohol and engaging in regular

217 physical exercise were positively associated with episodic memory scores. Depression scores

218 and the presence of chronic diseases were associated with lower memory scores.

219 Figure 2 illustrates the change in episodic memory scores over time. The graph is centred at

220 the first time an individual used hearing aids. It is centred on the point of time at which as

221 individual used hearing aids for the first time. The lines to the left of the centre of the graph

222 shows the rate of change in episodic memory score in the years leading up to beginning

223 hearing aid use, and the lines to the right of the centre of the graph shows the rate of change

224 in episodic memory following the beginning of hearing aid use. The model is adjusted for

225 demographic, socio-economic, lifestyle behaviour and health status. For all individuals, there

226 is a decline in episodic memory leading up to hearing aid use. The episodic memory scores

227 continue to decline after beginning to use hearing aids; however, the rate of decline is less 228 steep.

229 The first sensitivity analysis shows that both the immediate and delayed word recall scores

230 declined significantly before using hearing aids and this significant decline diminished after

231 beginning to use hearing aids (see Appendix 2 and 3). For the second sensitivity analysis (see

232 Appendix 4 and 5), we found that the slope of cognitive decline before and after beginning to

233 use hearing aids in the joint model is similar to that in the growth curve model. These

234 findings indicate that our findings are robust. Our final sensitivity analysis showed that

235 although females performed better than males in the episodic memory test, they have similar 
236 rate of cognitive decline before and after using hearing aids for the first time (see Appendix 6 237 and 7).

\section{Discussion}

239 Using a national representative survey spanning 18 years, our study shows a less steep

240 decrease in episodic memory performance after beginning to use hearing aids compared to

241 before using hearing aids. The reduced rate of decline following hearing aid use remained

242 significant after we took attrition into account. From the theoretical point of view, this

243 finding provides new evidence to disentangle the relationship between cognitive function and

244 hearing impairment. In prior studies, two main hypotheses have been posited to explain this

245 relationship. The 'common cause hypothesis' argues that hearing impairment and cognitive

246 decline share common age-related change factors such as the degeneration of the central

247 nervous system. ${ }^{30,31}$ The 'cascade hypothesis', on the other hand, claims that prolonged

248 reduction of hearing function leads to insufficient stimulation, which may in turn cause

249 cognitive decline in later life..$^{8,15,32,33}$ These hypotheses lead to different predictions regarding

250 on the impact of hearing aid use on cognition. According to the common cause hypotheses,

251 hearing aids may not affect cognition given that degeneration of central nervous system

252 affects regardless of the maintenance of good hearing function.

253 The slower rate of cognitive decline among those with hearing impairment who have begun

254 hearing aid use thus supports the cascade hypothesis. According to this hypothesis, hearing

255 aids may allow better hearing input and delay cognitive decline through either preventing the

256 adverse effects of auditory deprivation or facilitating lower levels of depression symptoms,

257 increased social engagement, and higher self-efficacy that have a positive impact on

258 cognitive function. Prior studies have reported that hearing aid users experienced less anxiety

259 and depression ${ }^{34,35}$ and better quality of social engagement after beginning to use hearing 
260 aids; both lower social engagement and depression are independently associated with

261 cognitive decline. ${ }^{37-39}$ Another mechanism through which hearing aids may reduce the rate

262 of cognitive decline is that they may enhance self-efficacy, the belief in one's own ability to

263 accomplish tasks or succeed in specific situations, ${ }^{40}$ which in turn improves scores on

264 cognitive tests and memory function. ${ }^{41,42}$ Further research is needed to confirm the

265 mechanism by which hearing aid use affects the rate of cognitive decline in later life.

266 The strengths of this study lie in its longer-term follow-up, which may have allowed greater

267 time for the accumulation of the benefits of hearing aid use to appear; the longer follow-up

268 period, however, also introduced greater individual differences that may influence cognitive

269 function due to the effects of ageing and disease. In addition, the population-based nature of

270 the HRS sample makes the results of the study generalizable and enhances their external

271 validity. Our findings could thus have substantial public health implications, especially

272 significant the large prevalence of age-related hearing impairment and poor hearing aid 273 uptake among those with hearing impairment. Approximately $33 \%$ adults aged $50+$ in the US

274 affected by hearing impairment ${ }^{43}$ and only $40 \%$ of those with moderate hearing impairment,

275 used hearing aids. ${ }^{44}$ A report from the National Academies of Sciences, Engineering, and

276 Medicine found that many individuals with hearing impairment do not seek or receive

277 hearing healthcare mainly due to their low awareness of hearing impairment, limited

278 accessibility of the care, and high costs for the hearing technologies. It further recommended

279 a set of actions to improve the accessibility and affordability of hearing healthcare, including

280 strengthen hearing healthcare promotion and provide access of the care for poor population.

$281{ }^{45}$ Our findings support the proposition that the timing of beginning hearing aid use is crucial

282 variable for the success of hearing aids as an intervention in old age. ${ }^{46}$ Furthermore,

283 Livingston et al. (2017) categorized hearing impairment as the most prominent midlife risk

284 factor for dementia ${ }^{3}$ with 55 years being the youngest average age at which the presence of 
285 hearing impairment was shown to be associated with increased risk of dementia. ${ }^{47}$ Preventing 286 hearing loss and/or screening individuals for hearing functioning and providing intervention 287 in the form of hearing aids may preserve cognitive function in older age.

288 A key limitation in our study is that hearing aid use was identified based on individuals 289 reporting whether they ever wear hearing aids. No information on the frequency of use, the 290 adequacy of amplification or individual's satisfaction with hearing aids was available. Up to $29140 \%$ of hearing aids dispensed are never or rarely used. ${ }^{48}$ Differing durations and extents of 292 rehabilitative procedures may also lead to different effects on cognitive function. These 293 differences may mask the magnitude of the effect of hearing aid use on cognitive function in 294 this study. As there is high inter-individual variability in hearing aid use, future studies 295 should consider this factor in their models. Another limitation of our study is that the episodic 296 memory tests in the HRS were all presented verbally, and improved hearing may facilitate 297 better performance of those tests. However, our analysis on the visually presented letter 298 cancellation test available in the English Longitudinal Data on Ageing (ELSA) Wave 5 299 shows that respondents with hearing impairment perform worse than those with no 300 impairment (see Appendix 8).

301 In sum, we observed a slower decline in episodic memory performance in HRS participants 302 with hearing impairment after beginning to use hearing aids. This association was shown to 303 be independent of risk factors for cognitive impairment and remained significant when we 304 considered attrition in the analysis. Public health efforts to increase access to quality hearing 305 healthcare might delay the onset of cognitive impairment and prove a successful preventive 306 intervention to reduce the impending dementia epidemic. 


\section{References}

309 1. Prince M., Wimo A, Guerchet M, et al. World Alzheimer Report 2015. The global 310 impact of dementia. An analysis of prevalence, incidence, cost \& trends. Alzheimer's Disease 311 International: London. 2015.

312 2. Ahmadi-Abhari S, Guzman-Castillo M, Bandosz P, et al. Temporal trend in dementia 313 incidence since 2002 and projections for prevalence in England and Wales to 2040: 314 Modelling study. BMJ 2017; 358: p. j2856.

315 3. Livingston G, Sommerlad A, Orgeta V, et al. Dementia prevention, intervention, and 316 care. The Lancet 2017; 390(10113): 2673-2734.

317 4. Maharani A, Piers D, Nazroo J. et al.; on behalf of the Sense-Cog WP1 group, 318 Sensory impairments and cognitive ageing: Evidence from the HRS, ELSA and SHARE. Age 319 and Ageing 2017. Insubmission.

320 5. Lin FR. Hearing loss and cognition among older adults in the United States. Journals

321 of Gerontology Series A: Biomedical Sciences and Medical Sciences 2011; 66(10): 11313221136.

323 6. Van Boxtel MPJ, Van Beijsterveldt CEM, Jolles PJ, et al. Mild hearing impairment 324 can reduce verbal memory performance in a healthy adult population. Journal of Clinical and 325 Experimental Neuropsychology 2000; 22(1): 147-154.

326 7. Tay T, Wang JJ, Kifley A, et al. Sensory and cognitive association in older persons:

327 findings from an older Australian population. Gerontology 2006; 52(6): 386-394. 
328 8. Lin FR, Yaffe K, Xia J, et al. Hearing loss and cognitive decline in older adults.

329 JAMA Internal Medicine 2013. 173(4): 293-299.

330 9. Deal JA, Sharrett AR, Albert MS, et al., Hearing impairment and cognitive decline: a

331 pilot study conducted within the atherosclerosis risk in communities neurocognitive study.

332 American Journal of Epidemiology 2015; 181(9): 680-690.

333 10. Valentijn SA, Van Boxtel MPJ, Van Hooren SAH, et al. Change in sensory 334 functioning predicts change in cognitive functioning: Results from a 6-year follow-up in the 335 Maastricht Aging Study. Journal of the American Geriatrics Society 2005; 53(3): 374-380.

336 11. Dawes P, Fortnum H, Moore DR, et al. Hearing in middle age: a population snapshot 337 of 40-69 year olds in the UK. Ear and Hearing 2014; 35(3): e44.

338 12. Chien W, Lin FR. Prevalence of hearing aid use among older adults in the United 339 States. Archives of Internal Medicine 2012; 172(3): 292-293.

340 13. Weinstein BE. Geriatric audiology. 2000: Thieme Medical Publishers.

341 14. Lin FR. Hearing loss in older adults: Who's listening? JAMA 2012; 307(11): 11473421148.

343 15. Dawes P, Emsley R, Cruickshanks KJ, et al. Hearing loss and cognition: The role of 344 hearing AIDS, social isolation and depression. PLoS One 2015; 10(3): e0119616.

345 16. Lin FR, Ferrucci L, Metter EJ, et al. Hearing loss and cognition in the Baltimore 346 Longitudinal Study of Aging. Neuropsychology 2011; 25(6): 763. 
347 17. Dawes P, Cruickshanks KJ, Fischer ME, et al. Hearing-aid use and long-term health

348 outcomes: Hearing handicap, mental health, social engagement, cognitive function, physical

349 health, and mortality. International Journal of Audiology 2015; 54(11): 838-844.

350 18. Kalluri S, Humes LE. Hearing technology and cognition. American Journal of 351 Audiology 2012; 21(2): 338-343.

352 19. Dere E, Easton A, Nadel L, et al. Handbook of episodic memory. Vol. 18. 2008:

353 Elsevier.

354 20. Bonsang E, Adam S, Perelman S. Does retirement affect cognitive functioning?

355 Journal of Health Economics 2012; 31(3): 490-501.

356 21. Tampubolon G, Nazroo J, Pendleton N. Trajectories of general cognition and 357 dementia in English older population: An exploration. European Geriatric Medicine 2017; 358 8(5-6): 454-459.

359 22. Marmot M, Friel S, Bell R, et al. Closing the gap in a generation: Health equity 360 through action on the social determinants of health. The Lancet 2008; 372(9650): 1661-1669.

361 23. Wilkinson RG, Marmot M. Social determinants of health: The solid facts. 2003:

362 World Health Organization.

363 24. Tampubolon G. Cognitive ageing in Great Britain in the new century: Cohort 364 differences in episodic memory. PloS One 2015; 10(12): e0144907.

365 25. Yaffe K. Chronic medical disease and cognitive aging: Toward a healthy body and 366 brain. 2013: Oxford University Press. 
367 26. Radloff LS. The CES-D scale: A self-report depression scale for research in the 368 general population. Applied Psychological Measurement 1977; 1(3): 385-401.

369 27. Chatfield MD, Brayne CE, Matthews FE. A systematic literature review of attrition 370 between waves in longitudinal studies in the elderly shows a consistent pattern of dropout 371 between differing studies. Journal of Clinical Epidemiology 2005; 58(1): 13-19.

372 28. Matthews FE, Chatfield M, Freeman C, et al., Attrition and bias in the MRC cognitive 373 function and ageing study: an epidemiological investigation. BMC Public Health 2004; 4(1): 37412.

375 29. Graham PL, Ryan LM, Luszcz MA. Joint modelling of survival and cognitive decline 376 in the Australian Longitudinal Study of Ageing. Journal of the Royal Statistical Society: 377 Series C (Applied Statistics) 2011; 60(2): 221-238.

378 30. Lindenberger U, Baltes PB. Sensory functioning and intelligence in old age: A strong 379 connection. Psychology and Aging 1994; 9(3): 339.

380 31. Lindenberger U, Ghisletta P. Cognitive and sensory declines in old age: gauging the 381 evidence for a common cause. Psychology and Aging 2009; 24(1): 1.

382 32. Wahl HW, Heyl V. Connections between vision, hearing, and cognitive function in 383 old age. Generations 2003; 27(1): 39-45.

384 33. Birren JE, The Psychology of Aging. 1964.

385 34. Joore MA, Potjewijd J, Timmerman AA, et al. Response shift in the measurement of 386 quality of life in hearing impaired adults after hearing aid fitting. Quality of Life Research 387 2002; 11(4): 299-307. 
388 35. Mulrow CD, Aguilar C, Endicott JE, et al. Quality-of-life changes and hearing 389 impairment. Ann Intern Med 1990; 113(3): 188-94.

390 36. Kochkin S, Rogin CM. Quantifying the obvious: The impact of hearing instruments 391 on quality of life. Hear Rev 2000; 7(1): 6-34.

392 37. Plassman BL, Williams JW, Burke JR, et al. Systematic review: Factors associated 393 with risk for and possible prevention of cognitive decline in later life. Annals of Internal 394 Medicine 2010; 153(3): 182-193.

395 38. Barnes LL, de Leon M, Wilson RS, et al. Social resources and cognitive decline in a 396 population of older African Americans and whites. Neurology 2004; 63(12): 2322-2326.

397 39. Steffens DC, Otey E, Alexopoulos GS, et al. Perspectives on depression, mild 398 cognitive impairment, and cognitive decline. Archives of General Psychiatry 2006; 63(2): $399 \quad 130-138$.

400 40. Bandura A. Self-efficacy: The exercise of control. 1997: Macmillan.

401 41. Artistico D, Berry JM, Black J, et al. Psychological functioning in adulthood: A self402 efficacy analysis. in Oxford Handbook of Reciprocal Adult Development and Learning, 403 edited by Carol Hoare, 215-247. 2nd ed. Oxford: Oxford University Press, 2011.

404 42. Kim KA, Mueller DJ. Memory, self-efficacy, and adaptability in Korean American 405 older adults: A collective study of four cases. Educational Gerontology: An International 406 Quarterly 1997; 23(5): 407-423.

407 43. Gopinath B, Rochtchina E, Wang JJ, et al. Prevalence of age-related hearing loss in 408 older adults: Blue Mountains Study. Archives of Internal Medicine 2009; 169(4): 415-418. 
409 44. Lin FR, Thorpe R, Gordon-Salant S, et al. Hearing loss prevalence and risk factors 410 among older adults in the United States. Journals of Gerontology Series A: Biomedical 411 Sciences and Medical Sciences 2011; 66(5): 582-590.

412 45. Blazer D, Liverman C, Domnitz S.Hearing Health Care: Priorities for Improving 413 Access and Affordability. National Academies of Sciences, Engineering, and Medicine. 414 2016. Washington, DC: National Academies Press.

415 46. Gelfand SA, Silman S, Ross L. Long-term effects of monaural, binaural and no 416 amplification in subjects with bilateral hearing loss. Scandinavian Audiology 1987; 16(4): $417 \quad 201-207$.

418 47. Gallacher J, Ilubaera V, Ben-Shlomo Y, et al. Auditory threshold, phonologic 419 demand, and incident dementia. Neurology 2012; 79(15): 1583-1590.

420 48. Vestergaard Knudsen, L., et al., Factors influencing help seeking, hearing aid uptake, 421 hearing aid use and satisfaction with hearing aids: A review of the literature. Trends in 422 amplification 2010. 14(3): p. 127-154. 


\section{$433 \quad$ List of tables}

434 Table 1 Characteristics of the HRS sample of hearing aids users (where using hearing aids 435 for the first time between wave 4 and wave 11) at baseline at the first wave observed

\begin{tabular}{|c|c|c|c|}
\hline & \multirow[t]{2}{*}{$\begin{array}{c}\text { Mean } \pm \text { SD } \\
(\%)\end{array}$} & \multicolumn{2}{|c|}{$\begin{array}{c}\text { Association with episodic memory } \\
\text { scores }\end{array}$} \\
\hline & & Cofficient (SE) & $P$ value \\
\hline Episodic memory scores & $10.4(3.2)$ & - & - \\
\hline Age & $62.83(7.73)$ & $-0.08(0.00)$ & $<0.001$ \\
\hline Female & 38.04 & $1.11(0.14)$ & $<0.001$ \\
\hline \multicolumn{4}{|l|}{ Education: } \\
\hline Primary school or less & 24.17 & reference & \\
\hline Secondary school & 30.2 & $1.68(0.19)$ & $<0.001$ \\
\hline College or higher & 45.64 & $2.52(0.17)$ & $<0.001$ \\
\hline Married & 81.66 & $0.28(0.18)$ & 0.128 \\
\hline \multicolumn{4}{|l|}{ Smoking behaviour: } \\
\hline Non-smoker & 38.48 & reference & \\
\hline Past smoker & 47.35 & $-0.26(0.16)$ & 0.101 \\
\hline Current smoker & 14.17 & $-0.38(0.23)$ & 0.102 \\
\hline Drinking behaviour (units/week) & $2.93(6.14)$ & $0.00(0.01)$ & 0.583 \\
\hline Doing vigorous physical activity & 51.18 & $0.53(0.14)$ & $<0.001$ \\
\hline Depression score & $1.14(1.72)$ & $-0.24(0.04)$ & $<0.001$ \\
\hline Number of comorbidities & $0.87(0.94)$ & $-0.38(0.07)$ & $<0.001$ \\
\hline
\end{tabular}


438 Table 2 Hearing aid use and episodic memory scores, coefficients and standard errors. 439 Source: HRS 1996-2014.

440

\begin{tabular}{|c|c|c|c|c|}
\hline & \multicolumn{2}{|c|}{ Model 1} & \multicolumn{2}{|c|}{ Model 2} \\
\hline & Cofficient (SE) & $P$ value & Cofficient (SE) & $P$ value \\
\hline Intercept & $17.89(0.36)$ & $<0.001$ & $15.32(0.4)$ & $<0.001$ \\
\hline Age (before using hearing aid) & $-0.11(0.00)$ & $<0.001$ & $-0.1(0.00)$ & $<0.001$ \\
\hline Age (after using hearing aid) & $-0.03(0.00)$ & $<0.001$ & $-0.02(0.00)$ & $<0.001$ \\
\hline Hearing aid use & $2.13(0.41)$ & $<0.001$ & $1.53(0.41)$ & $<0.001$ \\
\hline Female & & & $1.11(0.09)$ & $<0.001$ \\
\hline Married & & & $0.16(0.07)$ & 0.036 \\
\hline \multicolumn{5}{|l|}{ Education, ref: less than high } \\
\hline \multicolumn{5}{|l|}{ school } \\
\hline High school & & & $0.97(0.12)$ & $<0.001$ \\
\hline College or higher & & & $1.84(0.11)$ & $<0.001$ \\
\hline \multicolumn{5}{|l|}{ Wealth, ref: $1^{\text {st }}$ tertile (poorest) } \\
\hline $2^{\text {nd }}$ tertile & & & $0.33(0.07)$ & $<0.001$ \\
\hline $3^{\text {th }}$ tertile (wealthiest) & & & $0.58(0.08)$ & $<0.001$ \\
\hline \multirow{2}{*}{\multicolumn{5}{|c|}{$\begin{array}{l}\text { Smoking behaviour, ref: non- } \\
\text { smoker }\end{array}$}} \\
\hline & & & & \\
\hline Past smoker & & & $0.08(0.09)$ & 0.365 \\
\hline Current smoker & & & $-0.05(0.13)$ & 0.683 \\
\hline Drinking behaviour & & & $0.01(0.00)$ & 0.001 \\
\hline Doing vigorous physical activity & & & $0.17(0.05)$ & 0.001 \\
\hline Depression score & & & $-0.11(0.01)$ & $<0.001$ \\
\hline Number of comorbidities & & & $-0.13(0.03)$ & $<0.001$ \\
\hline
\end{tabular}


444 List of Figures

445 Figure 1 Procedure for the selection of sample $(\mathrm{N}=1,586)$ from the HRS core sample waves 446 3-12.

447

448

HRS core sample Waves 3-12 age 50+: 34,506 individuals

HRS core sample Waves 3-12 age 50+ with at Exclude 6,522 individuals who participated in two or fewer waves (model requirement)

HRS core sample Waves 3-12 age 50+ with at least 3 observations: 27,984 individuals

Exclude 25,724 individuals (already using hearing aids at Wave 3 or not using hearing aids by Wave 11). least 3 observations and start using hearing aids between Waves 4-11: 2,260 individuals

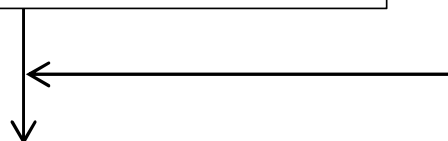

Exclude 220 individuals with dementia.

Final sample for analysis : 2,040 individuals. 622 of them participated in all 10 waves used in this study. Average of 7.2 (out of 10) observations per person. 
456 Figure 2 Predicted values of episodic memory before and after beginning to use hearing aids 457 (time centred at using hearing aids)

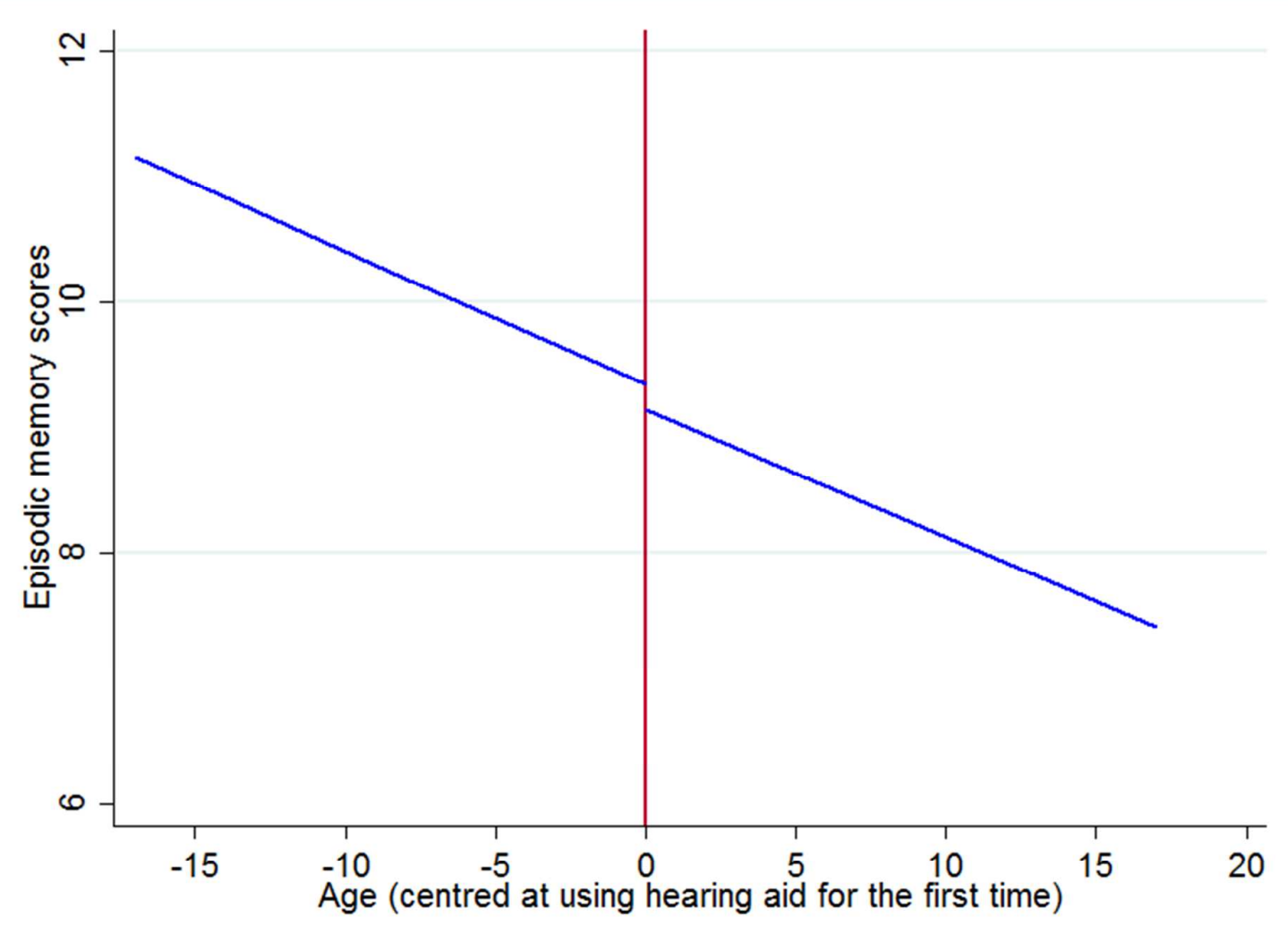

458

459 
460 Appendix 1 Descriptive statistics of full sample, sample with at least 3 observations and final sample of HRS Waves 3-12.

462

\begin{tabular}{lrrr}
\hline & $\begin{array}{c}\text { Wave 3-12 } \\
\text { sample at } \\
\text { baseline } \\
\mathrm{n}=34,506\end{array}$ & $\begin{array}{r}\text { Wave 3-12 } \\
\text { sample with at } \\
\text { least } 3 \\
\text { observations } \\
\mathrm{n}=27,984\end{array}$ & $\begin{array}{r}\text { Final sample } \\
\mathrm{n}=2,040\end{array}$ \\
\hline Episodic memory scores & $10.09(3.62)$ & $10.33(3.52)$ & $10.4(3.2)$ \\
Age & $62.22(10.56)$ & $61.29(9.67)$ & $62.83(7.73)$ \\
Female & 56.18 & 57.04 & 38.04 \\
Education: & & & \\
Primary school or less & 30.64 & 28.95 & 24.17 \\
Secondary school & 28.79 & 29.22 & 30.2 \\
College or higher & 40.58 & 41.83 & 45.64 \\
Married & 69.9 & 71.01 & 81.66 \\
Smoking behaviour: & & & \\
Non-smoker & 43.22 & 43.63 & 38.48 \\
Past smoker & 37.64 & 37.36 & 47.35 \\
Current smoker & 19.14 & 19.01 & 14.17 \\
Drinking behaviour & $2.71(8.94)$ & $2.67(6.81)$ & $2.93(6.14)$ \\
Doing vigorous physical activity & 42.48 & 44.92 & 51.18 \\
Depression score & $1.49(1.99)$ & $1.43(1.95)$ & $1.14(1.72)$ \\
Number of comorbidities & $0.93(1.01)$ & $0.83(0.94)$ & $0.87(0.94)$ \\
\hline
\end{tabular}


465 Appendix 2 Hearing aid use and immediate and delayed word recalls, coefficients and 466 467 standard errors. Source: HRS 1996-2014.

\begin{tabular}{|c|c|c|c|c|}
\hline & \multicolumn{2}{|c|}{ Immediate word recall } & \multicolumn{2}{|c|}{ Delayed word recall } \\
\hline & Cofficient (SE) & $P$ value & fficient (SE) & $P$ value \\
\hline Intercept & $8.18(0.2)$ & $<0.001$ & $7.15(0.23)$ & $<0.001$ \\
\hline Age (before using hearing aid) & $-0.05(0.00)$ & $<0.001$ & $-0.05(0.00)$ & $<0.001$ \\
\hline Age (after using hearing aid) & $-0.00(0.00)$ & 0.023 & $-0.01(0.00)$ & 0.014 \\
\hline Hearing aid use & $0.27(0.21)$ & 0.19 & $0.87(0.24)$ & $<0.001$ \\
\hline Female & $0.51(0.04)$ & $<0.001$ & $0.57(0.05)$ & $<0.001$ \\
\hline Married & $0.06(0.03)$ & 0.085 & $0.08(0.04)$ & 0.080 \\
\hline \multicolumn{5}{|l|}{ Education, ref: less than high } \\
\hline \multicolumn{5}{|l|}{ school } \\
\hline High school & $0.46(0.05)$ & $<0.001$ & $0.46(0.07)$ & $<0.001$ \\
\hline College or higher & $0.88(0.05)$ & $<0.001$ & $0.92(0.06)$ & $<0.001$ \\
\hline \multicolumn{5}{|l|}{ Wealth, ref: $1^{\text {st }}$ tertile (poorest) } \\
\hline $2^{\text {nd }}$ tertile & $0.16(0.03)$ & $<0.001$ & $0.14(0.04)$ & 0.001 \\
\hline $3^{\text {th }}$ tertile (wealthiest) & $0.26(0.04)$ & $<0.001$ & $0.28(0.05)$ & $<0.001$ \\
\hline \multirow{2}{*}{\multicolumn{5}{|c|}{$\begin{array}{l}\text { Smoking behaviour, ref: non- } \\
\text { smoker }\end{array}$}} \\
\hline & & & & \\
\hline Past smoker & $0.01(0.04)$ & 0.738 & $0.07(0.05)$ & 0.207 \\
\hline Current smoker & $-0.05(0.06)$ & 0.371 & $-0.00(0.07)$ & 0.988 \\
\hline Drinking regularly & $0.00(0.00)$ & 0.001 & $0.00(0.00)$ & 0.032 \\
\hline Doing vigorous physical activity & $0.06(0.02)$ & 0.015 & $0.09(0.03)$ & 0.001 \\
\hline Depression score & $-0.04(0.00)$ & $<0.001$ & $-0.05(0.00)$ & $<0.001$ \\
\hline Number of comorbidities & $-0.06(0.01)$ & $<0.001$ & $-0.05(0.01)$ & 0.002 \\
\hline
\end{tabular}


470 Appendix 3 Predicted values of immediate and delayed memory before and after beginning

471 to use hearing aids (time centred at using hearing aids)

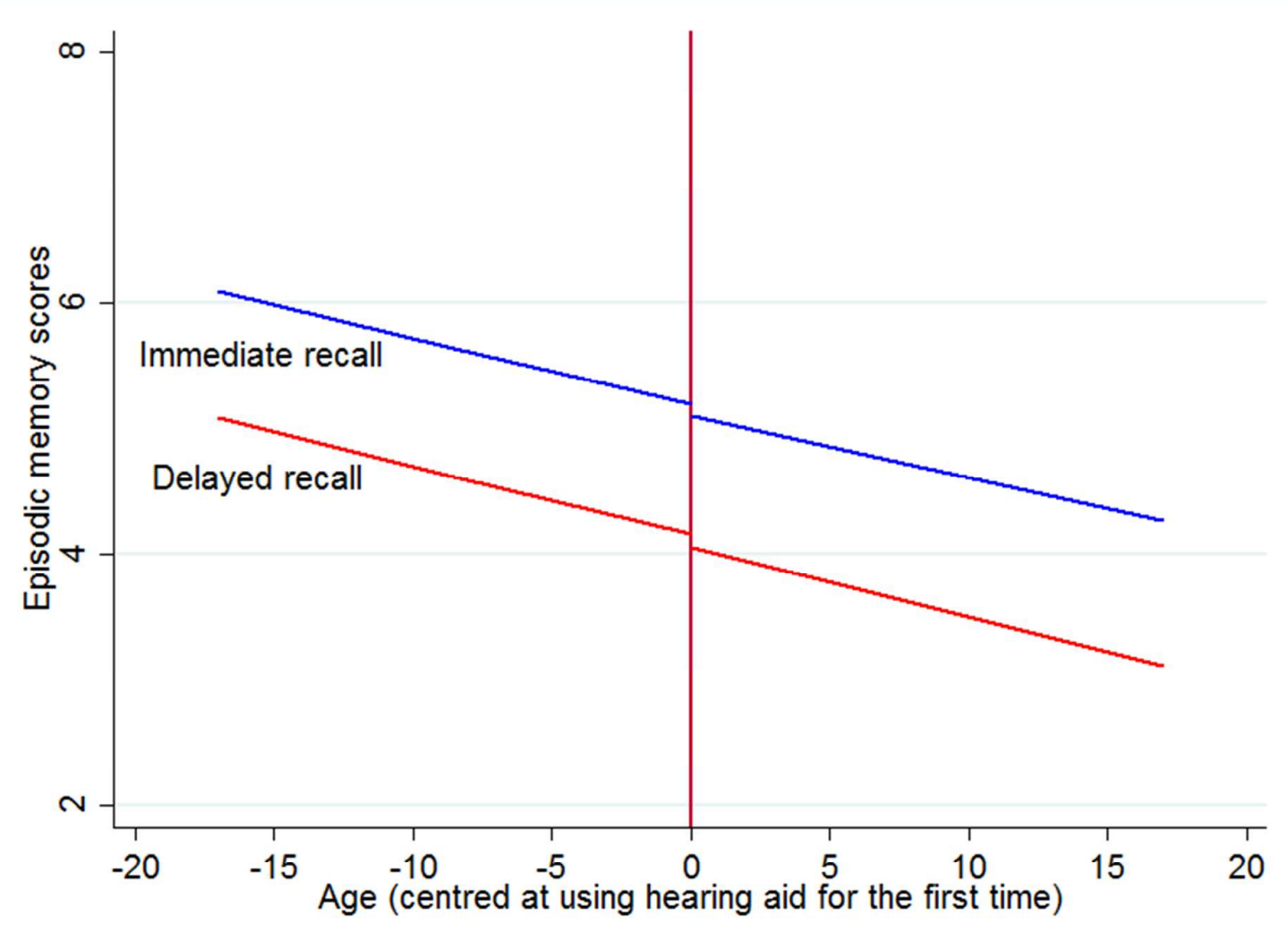


474 Appendix 4 Joint model predicting episodic memory scores. Source: HRS 1996-2014

\begin{tabular}{lrr}
\hline & Cofficient (SE) & P value \\
\hline Intercept & $15.62(0.26)$ & $<0.001$ \\
Age (before using hearing aid) & $-0.1(0.00)$ & $<0.001$ \\
Age (after using hearing aid) & $-0.02(0.00)$ & $<0.001$ \\
Hearing aid use & $0.68(0.31)$ & 0.031 \\
Female & $0.99(0.04)$ & $<0.001$ \\
Married & $0.05(0.06)$ & 0.42 \\
Education, ref: less than high school & & \\
High school & $0.84(0.08)$ & $<0.001$ \\
College or higher & $1.69(0.07)$ & $<0.001$ \\
Wealth, ref: $1^{\text {st }}$ tertile (poorest) & & \\
$2^{\text {nd }}$ tertile & $0.44(0.07)$ & $<0.001$ \\
$3^{\text {th }}$ tertile (wealthiest) & $0.7(0.07)$ & $<0.001$ \\
Smoking behaviour, ref: non-smoker & & \\
Past smoker & $-0.01(0.6)$ & 0.81 \\
Current smoker & $-0.06(0.1)$ & 0.51 \\
Drinking regularly & $0.47(0.09)$ & 0.009 \\
Doing vigorous physical activity & $0.18(0.05)$ & $<0.001$ \\
Depression score & $-0.14(0.01)$ & $<0.001$ \\
Number of comorbidities & $-0.1(0.02)$ & $<0.001$ \\
\hline
\end{tabular}

475

476 
477 Appendix 5 Predicted values of episodic memory using joint model before and after 478 beginning to use hearing aids (time centred at using hearing aids)

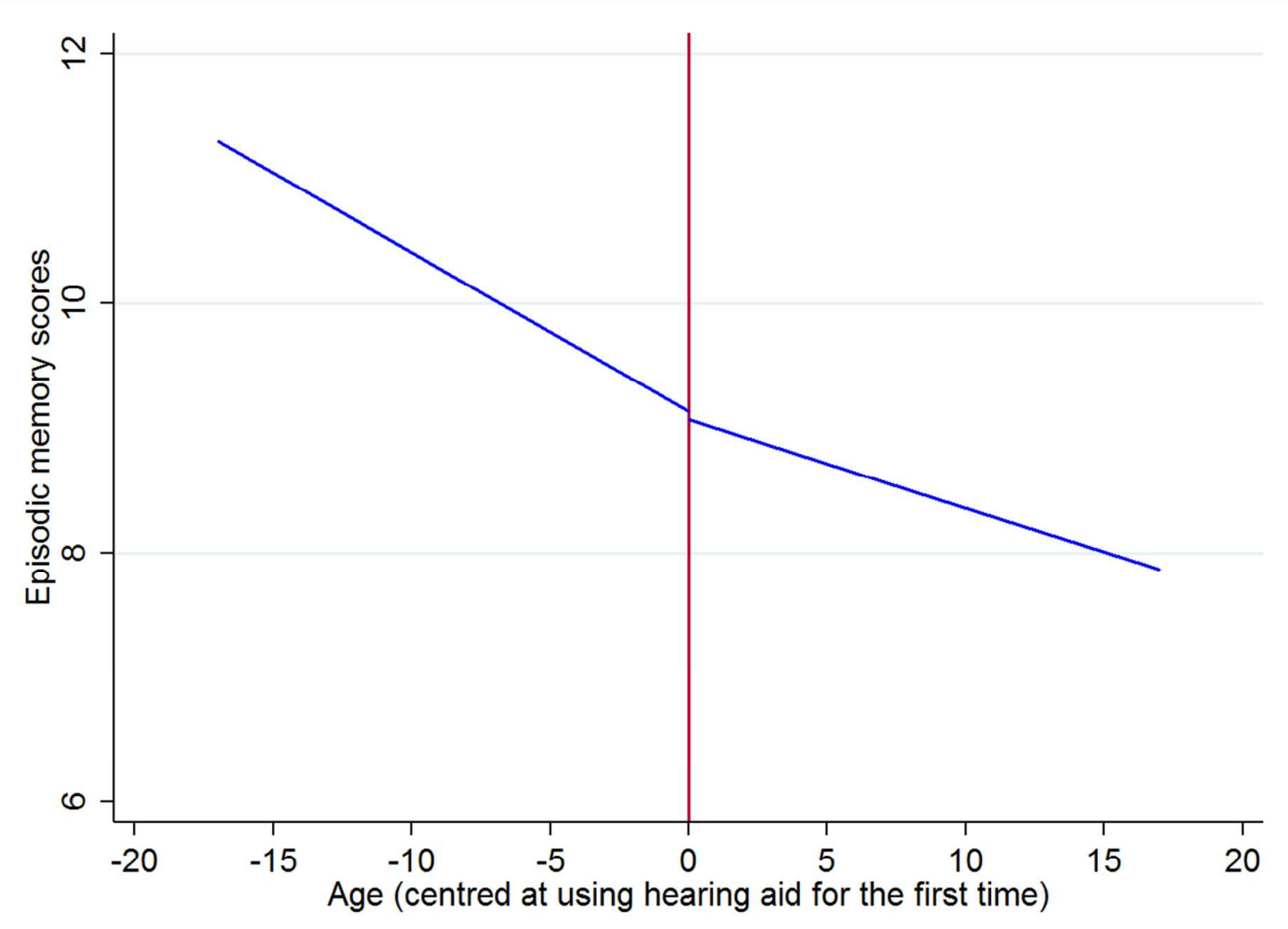

479

480 
481 Appendix 6 Hearing aid use and episodic memory scores by gender, coefficients and 482 483 standard errors. Source: HRS 1996-2014.

\begin{tabular}{|c|c|c|c|c|}
\hline & \multicolumn{2}{|c|}{ Females $(n=768)$} & \multicolumn{2}{|c|}{ Males $(n=1,227)$} \\
\hline & \multirow{2}{*}{$\begin{array}{l}\text { Cofficient (SE) } \\
17.065(0.62)\end{array}$} & $P$ value & officient (SE) & \multirow{2}{*}{$\begin{array}{c}\begin{array}{c}P \\
\text { value }\end{array} \\
<0.001\end{array}$} \\
\hline Intercept & & $<0.001$ & $14.884(0.51)$ & \\
\hline Age (before using hearing aid) & $-0.118(0.00)$ & $<0.001$ & $-0.103(0.00)$ & $<0.001$ \\
\hline Age (after using hearing aid) & $-0.029(0.00)$ & $<0.001$ & $-0.027(0.00)$ & $<0.001$ \\
\hline Hearing aid use & $1.605(0.65)$ & $<0.014$ & $1.509(0.53)$ & 0.004 \\
\hline Married & $-0.0008(0.11)$ & 0.994 & $0.302(0.11)$ & 0.007 \\
\hline \multicolumn{5}{|l|}{ Education, ref: less than high } \\
\hline \multicolumn{5}{|l|}{ school } \\
\hline High school & $1.021(0.21)$ & $<0.001$ & $0.953(0.15)$ & $<0.001$ \\
\hline College or higher & $1.722(0.2)$ & $<0.001$ & $1.934(0.14)$ & $<0.001$ \\
\hline \multicolumn{5}{|l|}{ Wealth, ref: $1^{\text {st }}$ tertile (poorest) } \\
\hline $2^{\text {nd }}$ tertile & $0.444(0.11)$ & $<0.001$ & $0.254(0.08)$ & $<0.001$ \\
\hline $3^{\text {th }}$ tertile (wealthiest) & $0.775(0.13)$ & $<0.001$ & $0.437(0.11)$ & $<0.001$ \\
\hline \multicolumn{5}{|l|}{$\begin{array}{l}\text { Smoking behaviour, ref: non- } \\
\text { smoker }\end{array}$} \\
\hline Past smoker & $0.107(0.15)$ & 0.497 & $0.067(0.12)$ & 0.598 \\
\hline Current smoker & $0.086(0.21)$ & 0.683 & $-0.132(0.17)$ & 0.439 \\
\hline Drinking behaviour & $0.001(0.01)$ & 0.924 & $0.019(0.00)$ & $<0.001$ \\
\hline Doing vigorous physical activity & $0.189(0.08)$ & 0.028 & $0.165(0.06)$ & 0.008 \\
\hline Depression score & $-0.101(0.02)$ & $<0.001$ & $-0.132(0.02)$ & $<0.001$ \\
\hline Number of comorbidities & $-0.14(0.05)$ & 0.008 & $-0.141(0.03)$ & $<0.001$ \\
\hline
\end{tabular}


487 Appendix 7 Predicted values of episodic memory before and after beginning to use hearing 488 aids (time centred at using hearing aids) by gender

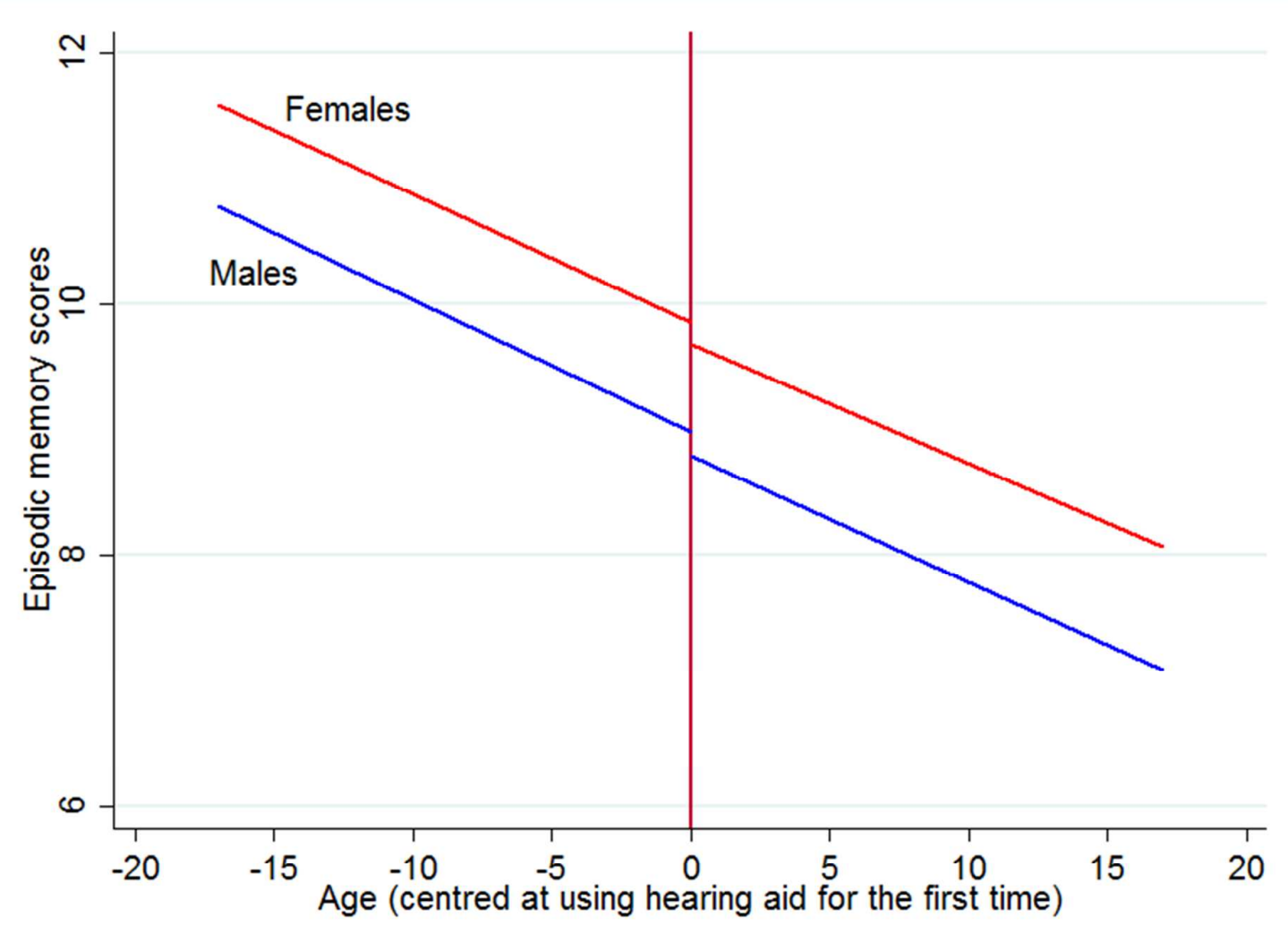

489

490 
491 Appendix 8 The comparison of letter cancellation performance between respondents with 492 different sensory function. Source: ELSA Wave 5 (2010).

493

\begin{tabular}{lrrr}
\hline & $\mathrm{N}$ & Mean & Standard deviation \\
\hline All sample & 10,274 & 18.91 & 5.4 \\
& & & \\
No hearing impairment & 8,121 & 19.22 & 5.44 \\
Hearing impairment & 2,142 & 17.66 & 5.3 \\
p-value* & $<0.001$ & & \\
& & & 5.3 \\
No visual impairment & 8,881 & 19.16 & 5.8 \\
Visual impairment & 1,381 & 17.03 & \\
p-value* & $<0.001$ & & \\
\hline
\end{tabular}

494

Note: $*$ : calculated using chi-square tests.

495

496

497 
1 Title : Longitudinal relationships between hearing aid use and cognitive function in older

2 Americans

3 Short running title : Hearing aid use and cognitive function in older adults

4 Author : Asri Maharani, $\mathrm{PhD},{ }^{1}$ Piers Dawes, $\mathrm{PhD},{ }^{2}$ James Nazroo, Professor, ${ }^{3}$ Gindo

5 Tampubolon, $\mathrm{PhD},{ }^{3}$ and Neil Pendleton, Professor, ${ }^{1}$ on behalf of the Sense-Cog WP1

6 group

7 Corresponding author: Asri Maharani

8 Address: Humanities Bridgeford Street Building G21, Oxford Road, Manchester M13 9PL,

9 United Kingdom

10 Telephone: +4416157025

11 Email address: asri.maharani@manchester.ac.uk

\section{Author affiliation and qualification:}

131 Division of Neuroscience and Experimental Psychology, School of Biological Sciences,

14 Faculty of Biology, Medicine and Health, University of Manchester, Manchester Academic

15 Health Science Centre, Manchester M13 9PL, United Kingdom

162 Division of Human Communication, Development \& Hearing, University of Manchester,

17 Oxford Road, Manchester M13 9PL, United Kingdom

183 Sociology and Cathie Marsh Institute for Social Research, University of Manchester

19 Humanities Bridgeford Street Building, Oxford Road, Manchester M13 9PL, United

20 Kingdom 


\section{Impact statement:}

22 We certify that this work is novel of recent novel clinical research. This manuscript is

23 important for the literature as it showed for the first time that cognitive decline at different

24 rate before and after the beginning of hearing aid use which holds an important public health

25 implication to improve cognitive health and prevent dementia among older people.

\section{Conflict of interest:}

27 The authors have no financial or any other kind of personal conflicts with this paper.

\section{Authors Contributions:}

29 AM, GT, JN, PD and NP made substantial contributions to the study design. AM analysed 30 the data. GT, JN, PD and NP contributed to the statistical design of the study. AM, GT, JN,

31 PD and NP contributed to the interpretation of the data and wrote each draft of the

32 manuscript. All authors critically reviewed and contributed significantly to the intellectual

33 content of the manuscript. AM had full access to all the data in the study and all authors had

34 final responsibility for the decision to submit for publication.

\section{Acknowledgement:}

36 The Sense-Cog WP1 group are Geir Bertelsen ${ }^{1,2}$, Suzanne $\operatorname{Cosh}^{3}$, Audrey Cougnard-

37 Grégoire $^{3}$, Cécile Delcourt ${ }^{3}$, Fofi Constantinidou ${ }^{4}$, Catherine Helmer ${ }^{3}$, M. Arfan Ikram ${ }^{5,6}$,

38 Caroline CW Klaver ${ }^{5,7}$, Iracema Leroi ${ }^{8}$, Magda Meester-Smor ${ }^{5,7}$, Unal Mutlu ${ }^{5,7}$, Virginie

$39 \mathrm{Nael}^{3,9,10}$, Henrik Schirmer ${ }^{11}$, Henning Tiemeier ${ }^{5,12}$, Therese von Hanno ${ }^{13,14}$.

40 1: UiT The Arctic University of Norway, Department of Community Medicine, Faculty of

41 Health Sciences, N-9037 Tromsø, Norway

42 2: University Hospital of North Norway, Department of Ophthalmology, N-9038 Tromsø,

43 Norway 
3: Univ. Bordeaux, Inserm, Bordeaux Population Health Research Center, team LEHA, UMR 1219, F-33000 Bordeaux, France

4: University of Cyprus, Department of Psychology \& Center for Applied Neuroscience, Nicosia, Cyprus

5: Erasmus Medical Centre, Department of Epidemiology, Rotterdam, The Netherlands

6: Erasmus Medical Centre, Departments of Neurology and Radiology, Rotterdam, The Netherlands

7: Erasmus Medical Centre, Department of Ophthalmology, Rotterdam, The Netherlands

8: University of Manchester, Division of Neuroscience and Experimental Psychology, School of Biological Sciences, Manchester, UK

9: Sorbonne University, UMPC University of Paris 06, INSERM, CNRS, Vision Institute, F75012 Paris, France

10: R\&D Life and Vision Science, Essilor International, F-75012 Paris, France

11: UiT-The Arctic University of Norway, Department of Clinical Medicine, Cardiovascular research Group-UNN, N-9037 Tromsø, Norway

12: Erasmus Medical Centre, Department of Psychiatry, Rotterdam, The Netherlands 13: UiT-The Arctic University of Norway, Department of Clinical Medicine, Faculty of Health Sciences, N-9037 Tromsø, Norway

14: Nordland Hospital, Department of Ophthalmology, N-8092 Bodø, Norway

\section{Funding source:}

45 This work was supported by SENSE-Cog project. This project has received funding from the 46 European Union's Horizon 2020 research and innovation programme under grant agreement $47 \quad$ No 668648.

48 Abstract word counts: 195 words 
49 Main document word counts: 2,991 999 words

50 Number of tables: 2 tables

51 Number of figures: 2 figures 


\section{Abstract}

54 Objective: To test whether hearing aid use alters cognitive trajectories in older adults.

55 Design, setting, and participants: Data were drawn from the Health and Retirement Study 56 (HRS), a US population-based longitudinal cohort study with cognitive performance 57 measured repeatedly every 2 years over 18 years (1996-2014). This study included 1,586 58 adults aged 50 and older who who took part in a minimum of three waves of the HRS and 59 who used hearing aids for the first time between Wave 4 and Wave 11.

60 Masurements: Cognitive outcomes were based on episodic memory scores determined by

61 the sum of immediate and delayed recall of 10 words.

62 Results: Hearing aid use was positively associated with episodic memory scores $(\beta=1.24$, $63 p<0.001)$. The decline in episodic memory scores was slower after $(\beta=-0.02, p<0.001)$ than 64 before using hearing aids $(\beta=-0.1, \quad p<0.001)$. These results were robust to adjustment for 65 multiple confounders and and to attrition as accounted for with joint model.

66 Conclusions: Hearing aids may have a mitigating impact on trajectories of cognitive decline 67 in later life. Providing hearing aids or other rehabilitative services for hearing impairment 68 much earlier in the course of hearing impairment may stem the worldwide rise of dementia.

69 Key words: Hearing aid use, cognition, longitudinal analysis 


\section{Introduction}

74 Neurodegenerative dementias such as Alzheimer disease are a major health problem in the

75 worldwide aging population. The number of people living with dementia is projected to

76 increase by $57 \%$ in the next two decades, from 46 million in 2015 to 72 million in 2050 . $^{1,2}$

77 This rising global prevalence, combined with the lack of effective curative treatment, has

78 rendered the prevention of dementia a public health concern.

79 A recent study by Livingston et al. (2017) showed that intervention on risk factors not 80 including hypertension might prevent $35 \%$ of dementia cases ${ }^{3}$ and that the strongest midlife

81 risk factor for dementia is hearing impairment. It showed that approximately $9 \%$ of dementia

82 cases are attributable to hearing loss in midlife. Our previous study, using three longitudinal

83 surveys on ageing health, showed that individuals with hearing and visual impairments had

84 lower episodic memory scores and a more adverse trajectory of decline in memory scores

85 with age than those with no impairment. ${ }^{4}$ The relationship between of hearing impairment

86 and lower cognitive ability in later life has also been reported by numerous cross-sectional ${ }^{5-7}$

87 and longitudinal studies. ${ }^{8-10}$ As sensory hearing impairment is prevalent, alleviating it partly

88 might have a great impact on when elderlydelay the point that older adults cross the critical

89 tine-threshold of impairment into dementia.

90 Hearing impairment as a risk factor for dementia is not only greater than other individual

91 midlife risks but is also relevant to many individuals because of its relatively high prevalence

92 in middle and old age. At least $10 \%$ of individuals aged 40 to 69 years show some degree of

93 measurable hearing impairment ${ }^{11}$ and that this proportion increases with age. The prevalence

94 of hearing impairment increases to $30 \%$ of individuals over the age of 65 , and between $70 \%$

95 and $90 \%$ individuals over the age of 85 experience some hearing loss. ${ }^{12,13}$ Although hearing

96 impairment is highly prevalent, it remains largely under treated. ${ }^{14}$ Only 1 in 7 adults aged 50+ 
97 with hearing impairment use hearing aids, and this figure declines to fewer than 1 in 20 for

98 working-aged adults (50-59 years old). ${ }^{12}$

99 The effect of hearing aid interventions on cognitive function remains poorly understood.

100 Cross-sectional studies from the $\mathrm{US}^{5}$ and the $\mathrm{UK}^{15}$ have reported that hearing aid use is

101 associated with better cognitive scores. In contrast, a study using a cross-sectional cohort of

102 the Baltimore Longitudinal Study of Aging found no significant relationship between hearing

103 aid use and cognitive ability. ${ }^{16}$ The insignificant effect of hearing aid use on cognitive

104 function was also shown in several small longitudinal studies of short duration. ${ }^{8-10,17,18}$

105 We used an 18-year follow-up of the Health and Retirement Study cohort to assess the 106 consequences of hearing aid use on long-term age-related decline in episodic memory. Using

107 a self-reported measure of hearing aid use, the association between hearing impairment and 108 cognitive trajectories over 18 years was investigated in a community-based cohort of older 109 adults, and the trajectories of the individuals before using hearing aids were compared with 110 those after beginning to use hearing aids.

\section{Methods}

112 This study forms part of the SENSE-Cog multi-phase research programme, funded by the 113 European Union Horizon 2020 programme. SENSE-Cog aims to promote mental well-being 114 in older adults with sensory and cognitive impairments (http://www.sense-cog.eu/). The first 115 work package of this project aims to better understand the links among sensory, cognitive and 116 mental ill-health in older Europeans. 
120 Our empirical analysis used the Health and Retirement Study (HRS) Waves 3 (1996-97) - 12

121 (2014-15). The HRS is an ongoing biennial investigation of US adults aged 50 years and

122 older that started in 1992. The respondents of the first wave were community-dwelling

123 Americans born between 1931 and 1941 and their partners. Since the fourth wave (1998), this

124 survey has also included participants from the Asset and Health Dynamies Among the Oldest

125 Old (AHEAD) study as well as a representative sample of individuals born between 1924 and

126 1947. Sponsored by the National Institute of Aging and performed by the Institute for Social

127 Research at the University of Michigan, the HRS provides information on demographic,

128 socio-economic factors, and health.

129 We used Wave 3 and later of the HRS as the episodic memory scores using 10 words were

130 first available in the third wave. In our study, we restricted the sample to respondents age 50

131 years and older who responded to at least three waves of HRS, had no dementia in the

132 baseline, and used hearing aids for the first time between Waves 4 and 11. This gave a

133 sample of 2,040 individuals with the selection procedure as illustrated in Figure 1 . We

134 describe the characteristics of the HRS core sample Waves 3-12, HRS core sample with at

135 least 3 observations and the final sample in Appendix 1. It shows that the average of age and

136 episodic memory scores of the core sample Waves 3-12 and final sample are similar.

\section{Measures}

138 The measures of cognitive ability in the HRS are the outcomes of simple tests, e.g. immediate 139 and delayed word recall (episodic memory), serial 7's test, backwards count starting from 20, 140 and date naming. In our analysis, we focused on one specific cognitive domain available in 141 all HRS waves used in this study: episodic memory. We were particularly interested in 
142 episodic memory scores as they are more age-sensitive than other cognitive measures, ${ }^{19}$ do 143 not suffer from floor or ceiling effects, ${ }^{20}$ have a common mechanism with cognitive control 144 variables $^{14}$ and have a strong association with dementia. After allowing for established risk 145 factors for dementia, the odds ratio for dementia among members of the most advantaged 146 trajectory of episodic memory was more than five times lower than the reference 147 (disadvantaged) trajectory. ${ }^{21}$ In the HRS memory test, the interviewer read a list of 10 simple 148 nouns (e.g. book, child, hotel, etc.) once and the participants were asked to repeat those nouns 149 on two occasions: immediately after the words were read out (immediate recall) and after a 150 short interval (delayed recall). Following Bonsang et al. (2012), ${ }^{20}+W \mathrm{We}$ calculated the 151 episodic memory score as the sum of the number of target words recalled at the immediate 152 and the delayed recall phase (score ranging from 0 to 20$). \underline{20}$

153 The timing of using hearing aids for the first time was based on self-definition through the 154 question: 'Do you ever wear a hearing aid?'. This question was posed to all respondents. 155 Based on the first time that respondents answered 'yes' to that question, we constructed a 156 dummy variable for hearing aid use ( 1 for the wave the first time the respondents used 157 hearing aids and after, 0 for the wave before the respondents used hearing aids). In total, 1581,586 respondents used hearing aids for the first time during the fourteen-year period.

159 We included an extensive set of covariates as identified as risk factors for cognitive decline in 160 prior studies. ${ }^{22-25}$ Demographic covariates included age (in years) and sex (female as the 161 reference). Socio-economic covariates included education (less than high school, high school, 162 and college or higher), marital status (married or cohabiting, and not married) and wealth 163 (tertiles of income each wave). Respondents' educational attainments were categorised as 164 less than high schøol (as the reference), high schøol, and college or higher. Marital status was 165 eategorised as married or cohabiting, and not married (as the reference). For wealth, we used 
166

167

168

169

170

171

172

173

174 To model trajectories in episodic memory scores, we used hierarchical linear regression

tertiles of income each year, using the poorest tertile as the reference. The lifestyle behaviour covariates included smoking, drinking behaviour and physical activities. For smoking behaviour, respondents were classified as non-smokers, past smokers and current smokers.

We used the number of units per week to measure drinking behaviour. Depressive symptoms were assessed with the 8-item Centre for Epidemiological Studies Depression Scale. ${ }^{26}$ Lastly, the number of comorbidities present was included as the sum of several chronic diseases: heart disease, high blood pressure, lung diseases, diabetes, stroke and cancer.

\section{Statistical analysis}

analysis, which is designed to analyse longitudinal data. In this regression analysis, intra-

176 individual correlation is modelled using an individual specific random intercept and an

177 individual specific random slope. This analysis thus takes into account multiple observations

178 within individual and intra-individual correlation. In addition, it allows for adjustment of 179 potential confounding variables. We used a spline model with a knot at the beginning of 180 hearing aid use and assessed whether the slope before using hearing aid differed to the post181 hearing aid use slope. We included the hearing aid variable (coded as 1 after using hearing 182 aids and 0 prior to using hearing aids) and its interaction with the slope term (age) to test the 183 differences in cognitive trajectories before and after beginning to use hearing aids. The 184 associations between hearing aid use, age, age interaction with hearing aid use and episodic 185 memory scores were quantified in the first model. The demographic and socio-economic 186 determinants (age, gender, education, marital status, and wealth) and the variables 187 representing lifestyle behaviour, depression, and the number of chronic diseases present were 188 added in the final model. 
191 For the first sensitivity analysis, we conducted two separated hierarchical linear regression 192 analyses with immediate and delayed word recall as the outcomes, while the second analysis

193 focused on attrition. The HRS, like other longitudinal studies on ageing is subject to attrition 194 in which respondents who drop-out are not a random sample. Respondents-are prone to 195 selective dropout due to death or poor health. ${ }^{27,28}$ Ignoring those dropouts thus can result in 196 bias in the analysis. We tested the sensitivity of our results to attrition by using a joint 197 model. $^{29}$ This resultant division into two parts, the growth curve model and the survival 198 model, allowed the random effects to influence both episodic memory and attrition. Finally, 199 we examined the role of gender in the association between hearing aid use and cognitive 200 function by conducting separate analyses for females and males. The models were 201 constructed using STATA 14 and Latent Gold 5.1.

\section{Results}

203 Table 1 shows the descriptive statistics of 2,040 HRS sample respondents who used hearing

204 aids for the first time between Waves 4 and 11 at the first wave observed. The episodic 205 memory score has a distribution close to the normal distribution with a sample mean of 10.4 206 and a standard deviation of 3.2. On average the respondents used hearing aids for the first 207 time at 63 years old. The respondents were mostly males (61\%) who had completed college 208 or higher $(45 \%)$ and were married $(81 \%)$. The bivariate regression model (see Table 1 , 209 second and third columns) shows that age, depression score, and number of comorbidities 210 have a negative and significant association with episodic memory scores. Being relatively

211 well educated, drinking alcohol and engaging regularly in physical activities are positively 212 associated with episodic memory scores. 
213 The parameter estimates for the slope of episodic memory scores before and after beginning

214 to use hearing aids in an initial model are presented in Table 2, left pane. Episodic memory 215 declined significantly with the addition of age, but the rate of the decline was slower after

216 beginning to use hearing aids $(\beta=-0.03, p<0.001)$ than before $(\beta=-0.11, p<0.001)$. The

217 difference of the coefficient between those two slopes is $0.08(p<0.001)$. In this model,

218 hearing aid use was associated with higher memory scores $(\beta=2.13, p<0.001)$. The

219 association between hearing aid use and episodic memory scores remained significant when

220 we included the risk factors in the second model $(\beta=1.24, p<0.001)$. In this second model,

221 slopes for the decline of episodic memory scores remained steeper before beginning hearing

222 aid use $(\beta=-0.1, p<0.001)$ than after $(\beta=-0.02, p<0.001)$.

223 In the second model, several potential confounders and socio-demographic characteristics

224 showed significant associations with episodic memory scores. Being female, having attained

225 a higher level of education, having a higher income, drinking alcohol and engaging in regular

226 physical exercise were positively associated with episodic memory scores. Depression scores

227 and the presence of chronic diseases were associated with lower memory scores.

228 Figure 2 illustrates the change in episodic memory scores over time. The graph is centred at 229 the first time an individual used hearing aids. It is centred on the point of time at which as 230 individual used hearing aids for the first time. The lines to the left of the centre of the graph 231 shows the rate of change in episodic memory score in the years leading up to beginning 232 hearing aid use, and the lines to the right of the centre of the graph shows the rate of change 233 in episodic memory following the beginning of hearing aid use. The model is adjusted for 234 demographic, socio-economic, lifestyle behaviour and health status. For all individuals, there 235 is a decline in episodic memory leading up to hearing aid use. The episodic memory scores 
236 continue to decline after beginning to use hearing aids; however, the rate of decline is less 237 steep.

238 The first sensitivity analysis shows that both the immediate and delayed word recall scores 239 declined significantly before using hearing aids $(\beta=0.05, p<0.001)$ and this significant 240 decline diminished after beginning to use hearing aids (see Appendix 2 and 3$)-(\beta=-0.00$,

$241 \quad p=0.023)$. Similarly, the delayed recall scores decline was gentler after $(\beta=0.05, p<0.001)$

242 than before the beginning of hearing aid use $(\beta=0.01, p=0.014)$. This sensitivity analysis

243 shows that our findings are robust.For the second sensitivity analysis (see Appendix $3 \underline{4}$ and

244 5), we found that the slope of cognitive decline before and after beginning to use hearing aids

245 in the joint model is similar to that in the growth curve model. These findings indicate that

246 our findings are robust. Our final sensitivity analysis showed that although females

247 performed better than males in the episodic memory test, they have similar rate of cognitive

248 decline before and after using hearing aids for the first time (see Appendix 6 and 7).

\section{Discussion}

250 Using a national representative survey spanning 18 years, our study shows a less steep

251 decrease in episodic memory performance after beginning to use hearing aids compared to

252 before using hearing aids. The reduced rate of decline following hearing aid use remained

253 significant after we took attrition into account. From the theoretical point of view, this

254 finding provides new evidence to disentangle the relationship between cognitive function and

255 hearing impairment. In prior studies, two main hypotheses have been posited to explain this

256 relationship. The 'common cause hypothesis' argues that hearing impairment and cognitive

257 decline share common age-related change factors such as the degeneration of the central

258 nervous system. ${ }^{30,31}$ The 'cascade hypothesis', on the other hand, claims that prolonged

259 reduction of hearing function leads to insufficient stimulation, which may in turn cause 
260 cognitive decline in later life..$^{8,15,32,33}$ These hypotheses lead to different predictions regarding

261 on the impact of hearing aid use on cognition. According to the common cause hypotheses,

262 hearing aids may not affect cognition given that degeneration of central nervous system

263 affects regardless of the maintenance of good hearing function.

264 The slower rate of cognitive decline among those with hearing impairment who have begun

265 hearing aid use thus supports the cascade hypothesis. According to this hypothesis, hearing

266 aids may allow better hearing input and delay cognitive decline through either preventing the

267 adverse effects of auditory deprivation or facilitating lower levels of depression symptoms,

268 increased social engagement, and higher self-efficacy that have a positive impact on

269 cognitive function. Prior studies have reported that hearing aid users experienced less anxiety

270 and depression ${ }^{34,35}$ and better quality of social engagement after beginning to use hearing

271 aids; both lower social engagement and depression are independently associated with

272 cognitive decline. ${ }^{37-39}$ Another mechanism through which hearing aids may reduce the rate

273 of cognitive decline is that they may enhance self-efficacy, the belief in one's own ability to

274 accomplish tasks or succeed in specific situations, ${ }^{40}$ which in turn improves scores on

275 cognitive tests and memory function. ${ }^{41,42}$ Further research is needed to confirm the

276 mechanism by which hearing aid use affects the rate of cognitive decline in later life.

277 The strengths of this study lie in its longer-term follow-up, which may have allowed greater

278 time for the accumulation of the benefits of hearing aid use to appear; the longer follow-up

279 period, however, also introduced greater individual differences that may influence cognitive

280 function due to the effects of ageing and disease. In addition, the population-based nature of

281 the HRS sample makes the results of the study generalizable and enhances their external

282 validity. Our findings could thus have substantial public health implications, especially

283 significant the large prevalence of age-related hearing impairment and poor hearing aid 
284 uptake among those with hearing impairment. Approximately $33 \%$ adults aged $50+$ in the US

285 affected by hearing impairment ${ }^{43}$ and only $40 \%$ of those with moderate hearing impairment,

286 used hearing aids. ${ }^{44}$ A report from the National Academies of Sciences, Engineering, and

287 Medicine found that many individuals with hearing impairment do not seek or receive

288 hearing healthcare mainly due to their low awareness of hearing impairment, limited

289 accessibility of the care, and high costs for the hearing technologies. It further recommended

290 a set of actions to improve the accessibility and affordability of hearing healthcare, including

291 strengthen hearing healthcare promotion and provide access of the care for poor population.

$292 \quad{ }^{45}$ Our findings support the proposition that the timing of beginning hearing aid use is crucial

293 variable for the success of hearing aids as an intervention in old age. ${ }^{45}{ }^{46}$ Furthermore,

294 Livingston et al. (2017) categorized hearing impairment as the most prominent midlife risk

295 factor for dementia ${ }^{3}$ with 55 years being the youngest average age at which the presence of

296 hearing impairment was shown to be associated with increased risk of dementia. ${ }^{46}-\frac{47}{}$

297 Preventing hearing loss and/or screening individuals for hearing functioning and providing

298 intervention in the form of hearing aids may preserve cognitive function in older age.

299 A key limitation in our study is that hearing aid use was identified based on individuals

300 reporting whether they ever wear hearing aids. No information on the frequency of use, the

301 adequacy of amplification or individual's satisfaction with hearing aids was available. Up to

$30240 \%$ of hearing aids dispensed are never or rarely used. ${ }^{47}{ }_{-}^{48}$ Differing durations and extents of 303 rehabilitative procedures may also lead to different effects on cognitive function. These

304 differences may mask the magnitude of the effect of hearing aid use on cognitive function in

305 this study. As there is high inter-individual variability in hearing aid use, future studies

306 should consider this factor in their models. Another limitation of our study is that the episodic

307 memory tests in the HRS were all presented verbally, and improved hearing may facilitate

308 better performance of those tests. However, our analysis on the visually presented letter 
309 cancellation test available in the English Longitudinal Data on Ageing (ELSA) Wave 5

310 shows that respondents with hearing impairment perform worse than those with no

311 impairment (see Appendix 4ㅇ).

312 In sum, we observed a slower decline in episodic memory performance in HRS participants

313 with hearing impairment after beginning to use hearing aids. This association was shown to

314 be independent of risk factors for cognitive impairment and remained significant when we

315 considered attrition in the analysis. Public health efforts to increase access to quality hearing

316 healthcare might delay the onset of cognitive impairment and prove a successful preventive

317 intervention to reduce the impending dementia epidemic. 


\section{References}

320 1. Prince M., Wimo A, Guerchet M, et al. World Alzheimer Report 2015. The global 321 impact of dementia. An analysis of prevalence, incidence, cost \& trends. Alzheimer's Disease 322 International: London. 2015.

323 2. Ahmadi-Abhari S, Guzman-Castillo M, Bandosz P, et al. Temporal trend in dementia 324 incidence since 2002 and projections for prevalence in England and Wales to 2040: 325 Modelling study. BMJ 2017; 358: p. j2856.

326 3. Livingston G, Sommerlad A, Orgeta V, et al. Dementia prevention, intervention, and 327 care. The Lancet 2017; 390(10113): 2673-2734.

328 4. Maharani A, Piers D, Nazroo J. et al.; on behalf of the Sense-Cog WP1 group, 329 Sensory impairments and cognitive ageing: Evidence from the HRS, ELSA and SHARE. Age 330 and Ageing 2017. Insubmission.

331 5. Lin FR. Hearing loss and cognition among older adults in the United States. Journals 332 of Gerontology Series A: Biomedical Sciences and Medical Sciences 2011; 66(10): 11313331136.

334 6. Van Boxtel MPJ, Van Beijsterveldt CEM, Jolles PJ, et al. Mild hearing impairment 335 can reduce verbal memory performance in a healthy adult population. Journal of Clinical and 336 Experimental Neuropsychology 2000; 22(1): 147-154.

337 7. Tay T, Wang JJ, Kifley A, et al. Sensory and cognitive association in older persons: 338 findings from an older Australian population. Gerontology 2006; 52(6): 386-394. 
339 8. Lin FR, Yaffe K, Xia J, et al. Hearing loss and cognitive decline in older adults.

340 JAMA Internal Medicine 2013. 173(4): 293-299.

341 9. Deal JA, Sharrett AR, Albert MS, et al., Hearing impairment and cognitive decline: a 342 pilot study conducted within the atherosclerosis risk in communities neurocognitive study. 343 American Journal of Epidemiology 2015; 181(9): 680-690.

344 10. Valentijn SA, Van Boxtel MPJ, Van Hooren SAH, et al. Change in sensory 345 functioning predicts change in cognitive functioning: Results from a 6-year follow-up in the 346 Maastricht Aging Study. Journal of the American Geriatrics Society 2005; 53(3): 374-380.

347 11. Dawes P, Fortnum H, Moore DR, et al. Hearing in middle age: a population snapshot 348 of 40-69 year olds in the UK. Ear and Hearing 2014; 35(3): e44.

349 12. Chien W, Lin FR. Prevalence of hearing aid use among older adults in the United 350 States. Archives of Internal Medicine 2012; 172(3): 292-293.

351 13. Weinstein BE. Geriatric audiology. 2000: Thieme Medical Publishers.

352 14. Lin FR. Hearing loss in older adults: Who's listening? JAMA 2012; 307(11): 11473531148.

354 15. Dawes P, Emsley R, Cruickshanks KJ, et al. Hearing loss and cognition: The role of 355 hearing AIDS, social isolation and depression. PLoS One 2015; 10(3): e0119616.

356 16. Lin FR, Ferrucci L, Metter EJ, et al. Hearing loss and cognition in the Baltimore 357 Longitudinal Study of Aging. Neuropsychology 2011; 25(6): 763. 
358 17. Dawes P, Cruickshanks KJ, Fischer ME, et al. Hearing-aid use and long-term health 359 outcomes: Hearing handicap, mental health, social engagement, cognitive function, physical 360 health, and mortality. International Journal of Audiology 2015; 54(11): 838-844.

361 18. Kalluri S, Humes LE. Hearing technology and cognition. American Journal of 362 Audiology 2012; 21(2): 338-343.

363 19. Dere E, Easton A, Nadel L, et al. Handbook of episodic memory. Vol. 18. 2008: 364 Elsevier.

365 20. Bonsang E, Adam S, Perelman S. Does retirement affect cognitive functioning? 366 Journal of Health Economics 2012; 31(3): 490-501.

367 21. Tampubolon G, Nazroo J, Pendleton N. Trajectories of general cognition and 368 dementia in English older population: An exploration. European Geriatric Medicine 2017; 369 8(5-6): 454-459.

370 22. Marmot M, Friel S, Bell R, et al. Closing the gap in a generation: Health equity

371 through action on the social determinants of health. The Lancet 2008; 372(9650): 1661-1669.

372 23. Wilkinson RG, Marmot M. Social determinants of health: The solid facts. 2003:

373 World Health Organization.

374 24. Tampubolon G. Cognitive ageing in Great Britain in the new century: Cohort 375 differences in episodic memory. PloS One 2015; 10(12): e0144907.

376 25. Yaffe K. Chronic medical disease and cognitive aging: Toward a healthy body and 377 brain. 2013: Oxford University Press. 
378 26. Radloff LS. The CES-D scale: A self-report depression scale for research in the 379 general population. Applied Psychological Measurement 1977; 1(3): 385-401.

380 27. Chatfield MD, Brayne CE, Matthews FE. A systematic literature review of attrition 381 between waves in longitudinal studies in the elderly shows a consistent pattern of dropout 382 between differing studies. Journal of Clinical Epidemiology 2005; 58(1): 13-19.

383 28. Matthews FE, Chatfield M, Freeman C, et al., Attrition and bias in the MRC cognitive 384 function and ageing study: an epidemiological investigation. BMC Public Health 2004; 4(1): 38512.

386 29. Graham PL, Ryan LM, Luszcz MA. Joint modelling of survival and cognitive decline 387 in the Australian Longitudinal Study of Ageing. Journal of the Royal Statistical Society: 388 Series C (Applied Statistics) 2011; 60(2): 221-238.

389 30. Lindenberger U, Baltes PB. Sensory functioning and intelligence in old age: A strong 390 connection. Psychology and Aging 1994; 9(3): 339.

391 31. Lindenberger U, Ghisletta P. Cognitive and sensory declines in old age: gauging the 392 evidence for a common cause. Psychology and Aging 2009; 24(1): 1.

393 32. Wahl HW, Heyl V. Connections between vision, hearing, and cognitive function in 394 old age. Generations 2003; 27(1): 39-45.

395 33. Birren JE, The Psychology of Aging. 1964.

396 34. Joore MA, Potjewijd J, Timmerman AA, et al. Response shift in the measurement of 397 quality of life in hearing impaired adults after hearing aid fitting. Quality of Life Research 398 2002; 11(4): 299-307. 
399 35. Mulrow CD, Aguilar C, Endicott JE, et al. Quality-of-life changes and hearing 400 impairment. Ann Intern Med 1990; 113(3): 188-94.

401 36. Kochkin S, Rogin CM. Quantifying the obvious: The impact of hearing instruments 402 on quality of life. Hear Rev 2000; 7(1): 6-34.

403 37. Plassman BL, Williams JW, Burke JR, et al. Systematic review: Factors associated 404 with risk for and possible prevention of cognitive decline in later life. Annals of Internal 405 Medicine 2010; 153(3): 182-193.

406 38. Barnes LL, de Leon M, Wilson RS, et al. Social resources and cognitive decline in a 407 population of older African Americans and whites. Neurology 2004; 63(12): 2322-2326.

408 39. Steffens DC, Otey E, Alexopoulos GS, et al. Perspectives on depression, mild 409 cognitive impairment, and cognitive decline. Archives of General Psychiatry 2006; 63(2): $410 \quad 130-138$.

411 40. Bandura A. Self-efficacy: The exercise of control. 1997: Macmillan.

412 41. Artistico D, Berry JM, Black J, et al. Psychological functioning in adulthood: A self413 efficacy analysis. in Oxford Handbook of Reciprocal Adult Development and Learning, 414 edited by Carol Hoare, 215-247. 2nd ed. Oxford: Oxford University Press, 2011.

415 42. Kim KA, Mueller DJ. Memory, self-efficacy, and adaptability in Korean American 416 older adults: A collective study of four cases. Educational Gerontology: An International 417 Quarterly 1997; 23(5): 407-423.

418 43. Gopinath B, Rochtchina E, Wang JJ, et al. Prevalence of age-related hearing loss in 419 older adults: Blue Mountains Study. Archives of Internal Medicine 2009; 169(4): 415-418. 
420 44. Lin FR, Thorpe R, Gordon-Salant S, et al. Hearing loss prevalence and risk factors 421 among older adults in the United States. Journals of Gerontology Series A: Biomedical

422 Sciences and Medical Sciences 2011; 66(5): 582-590.

423 45. Blazer D, Liverman C, Domnitz S.Hearing Health Care: Priorities for Improving Access and Affordability. National Academies of Sciences, Engineering, and Medicine. 2016. Washington, DC: National Academies Press. amplification in subjects with bilateral hearing loss. Scandinavian Audiology 1987; 16(4): $429 \quad 201-207$. demand, and incident dementia. Neurology 2012; 79(15): 1583-1590. 
List of tables

446 Table 1 Characteristics of the HRS sample of hearing aids users (where using hearing aids

447 for the first time between wave 4 and wave 11) at baseline at the first wave observed

\begin{tabular}{lrrr}
\hline & $\begin{array}{c}\text { Mean } \pm \text { SD } \\
\text { (\%) }\end{array}$ & \multicolumn{2}{c}{$\begin{array}{c}\text { Association with episodic memory } \\
\text { scores }\end{array}$} \\
\cline { 3 - 4 } & & Cofficient (SE) & P value \\
\hline Episodic memory scores & $10.4(3.2)$ & - & - \\
Age & $62.83(7.73)$ & $-0.08(0.00)$ & $<0.001$ \\
Female & 38.04 & $1.11(0.14)$ & $<0.001$ \\
Education: & & & \\
Primary school or less & 24.17 & reference & \\
Secondary school & 30.2 & $1.68(0.19)$ & $<0.001$ \\
College or higher & 45.64 & $2.52(0.17)$ & $<0.001$ \\
Married & 81.66 & $0.28(0.18)$ & 0.128 \\
Smoking behaviour: & & & \\
Non-smoker & 38.48 & reference & \\
Past smoker & 47.35 & $-0.26(0.16)$ & 0.101 \\
Current smoker & 14.17 & $-0.38(0.23)$ & 0.102 \\
Drinking behaviour (units/week) & $2.93(6.14)$ & $0.00(0.01)$ & 0.583 \\
Doing vigorous physical activity & 51.18 & $0.53(0.14)$ & $<0.001$ \\
Depression score & $1.14(1.72)$ & $-0.24(0.04)$ & $<0.001$ \\
Number of comorbidities & $0.87(0.94)$ & $-0.38(0.07)$ & $<0.001$ \\
\hline
\end{tabular}


450 Table 2 Hearing aid use and episodic memory scores, coefficients and standard errors. 451 Source: HRS 1996-2014.

452

\begin{tabular}{|c|c|c|c|c|}
\hline & \multicolumn{2}{|c|}{ Model 1} & \multicolumn{2}{|c|}{ Model 2} \\
\hline & Cofficient (SE) & $P$ value & Cofficient (SE) & $P$ value \\
\hline Intercept & $17.89(0.36)$ & $<0.001$ & $15.32(0.4)$ & $<0.001$ \\
\hline Age (before using hearing aid) & $-0.11(0.00)$ & $<0.001$ & $-0.1(0.00)$ & $<0.001$ \\
\hline Age (after using hearing aid) & $-0.03(0.00)$ & $<0.001$ & $-0.02(0.00)$ & $<0.001$ \\
\hline Hearing aid use & $2.13(0.41)$ & $<0.001$ & $1.53(0.41)$ & $<0.001$ \\
\hline Female & & & $1.11(0.09)$ & $<0.001$ \\
\hline Married & & & $0.16(0.07)$ & 0.036 \\
\hline \multicolumn{5}{|l|}{ Education, ref: less than high } \\
\hline \multicolumn{5}{|l|}{ school } \\
\hline High school & & & $0.97(0.12)$ & $<0.001$ \\
\hline College or higher & & & $1.84(0.11)$ & $<0.001$ \\
\hline \multicolumn{5}{|l|}{ Wealth, ref: $1^{\text {st }}$ tertile (poorest) } \\
\hline $2^{\text {nd }}$ tertile & & & $0.33(0.07)$ & $<0.001$ \\
\hline $3^{\text {th }}$ tertile (wealthiest) & & & $0.58(0.08)$ & $<0.001$ \\
\hline \multirow{2}{*}{\multicolumn{5}{|c|}{$\begin{array}{l}\text { Smoking behaviour, ref: non- } \\
\text { smoker }\end{array}$}} \\
\hline & & & & \\
\hline Past smoker & & & $0.08(0.09)$ & 0.365 \\
\hline Current smoker & & & $-0.05(0.13)$ & 0.683 \\
\hline Drinking behaviour & & & $0.01(0.00)$ & 0.001 \\
\hline Doing vigorous physical activity & & & $0.17(0.05)$ & 0.001 \\
\hline Depression score & & & $-0.11(0.01)$ & $<0.001$ \\
\hline Number of comorbidities & & & $-0.13(0.03)$ & $<0.001$ \\
\hline
\end{tabular}


HRS core sample Waves 3-12 age 50+: 34,506 individuals

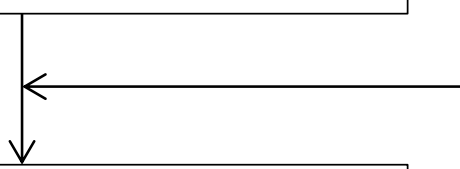

Exclude 6,522 individuals who participated in two or fewer waves (model requirement)

HRS core sample Waves 3-12 age 50+ with at least 3 observations: 27,984 individuals

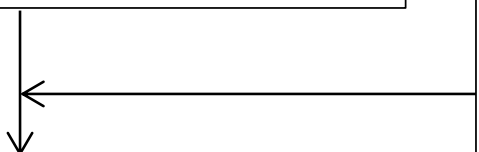

Exclude 25,724 individuals (already using hearing aids at Wave 3 or not using hearing aids by Wave 11).

HRS core sample Waves 3-12 age 50+ with at least 3 observations and start using hearing aids between Waves 4-11: 2,260 individuals
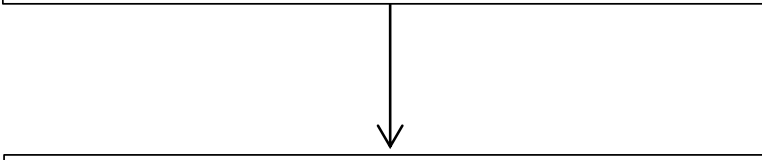

Exclude 220 individuals with dementia.

Final sample for analysis : 2,040 individuals. 622 of them participated in all 10 waves used in this study. Average of 7.2 (out of 10) observations per person. 


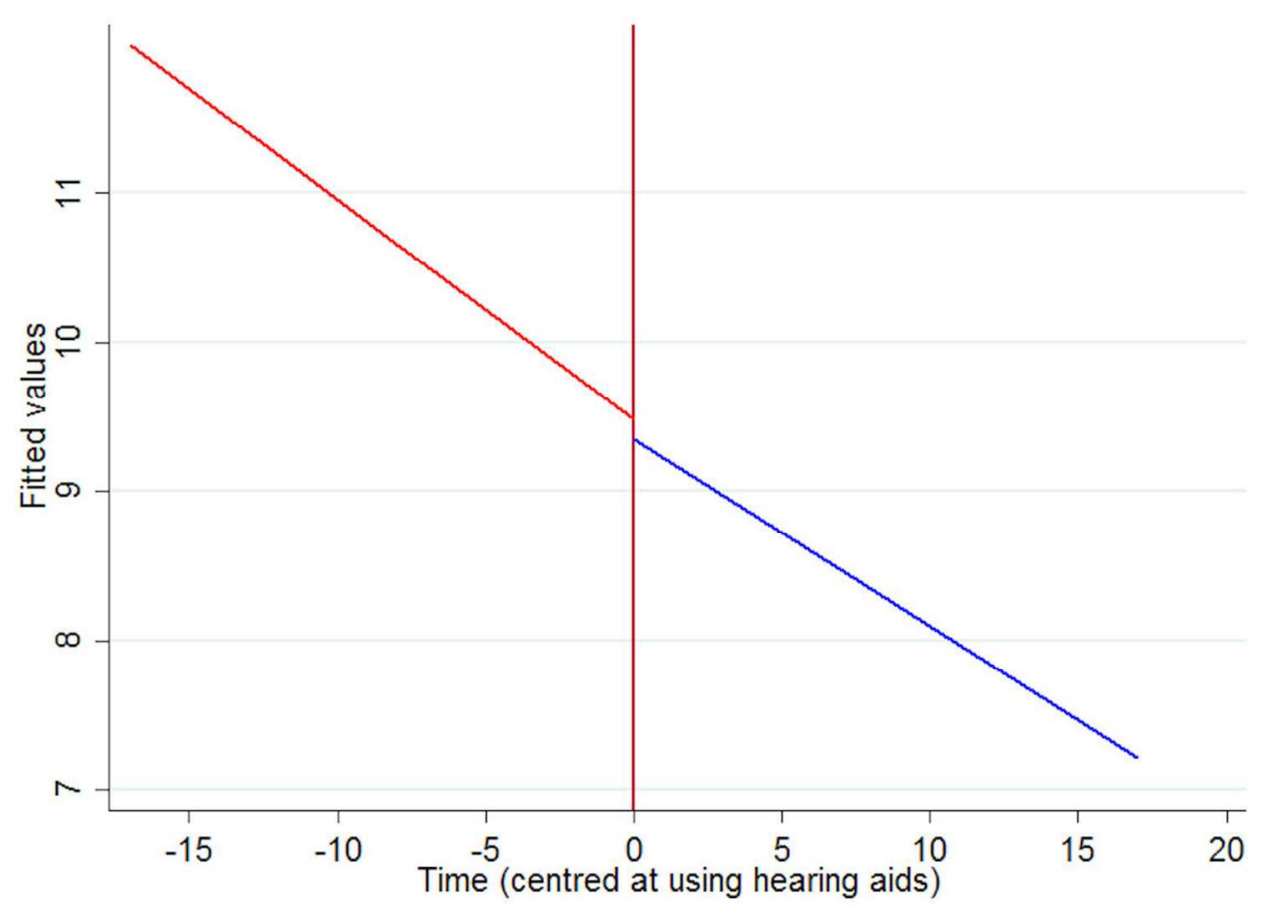

Predicted values of episodic memory before and after beginning to use hearing aids (time centred at using hearing aids)

$99 \times 72 \mathrm{~mm}(300 \times 300 \mathrm{DPI})$ 
Appendix 1 Descriptive statistics of full sample, sample with at least 3 observations and final sample of HRS Waves 3-12.

\begin{tabular}{lrrr}
\hline & $\begin{array}{c}\text { Wave 3-12 } \\
\text { sample at } \\
\text { baseline } \\
\mathrm{n}=34,506\end{array}$ & $\begin{array}{r}\text { Wave 3-12 } \\
\text { sample with at } \\
\text { least 3 } \\
\text { observations } \\
\mathrm{n}=27,984\end{array}$ & $\begin{array}{r}\text { Final sample } \\
\mathrm{n}=2,040\end{array}$ \\
\hline Episodic memory scores & $10.09(3.62)$ & $10.33(3.52)$ & $10.4(3.2)$ \\
Age & $62.22(10.56)$ & $61.29(9.67)$ & $62.83(7.73)$ \\
Female & 56.18 & 57.04 & 38.04 \\
Education: & & & \\
Primary school or less & 30.64 & 28.95 & 24.17 \\
Secondary school & 28.79 & 29.22 & 30.2 \\
College or higher & 40.58 & 41.83 & 45.64 \\
Married & 69.9 & 71.01 & 81.66 \\
Smoking behaviour: & & & \\
Non-smoker & 43.22 & 43.63 & 38.48 \\
Past smoker & 37.64 & 37.36 & 47.35 \\
Current smoker & 19.14 & 19.01 & 14.17 \\
Drinking behaviour & $2.71(8.94)$ & $2.67(6.81)$ & $2.93(6.14)$ \\
Doing vigorous physical activity & 42.48 & 44.92 & 51.18 \\
Depression score & $1.49(1.99)$ & $1.43(1.95)$ & $1.14(1.72)$ \\
Number of comorbidities & $0.93(1.01)$ & $0.83(0.94)$ & $0.87(0.94)$ \\
\hline
\end{tabular}


Appendix 2 Hearing aid use and immediate and delayed word recalls, coefficients and standard errors. Source: HRS 1996-2014.

\begin{tabular}{|c|c|c|c|c|}
\hline & \multicolumn{2}{|c|}{ Immediate word recall } & \multicolumn{2}{|c|}{ Delayed word recall } \\
\hline & Cofficient (SE) & $P$ value & Cofficient (SE) & $P$ value \\
\hline Intercept & $8.18(0.2)$ & $<0.001$ & $7.15(0.23)$ & $<0.001$ \\
\hline Age (before using hearing aid) & $-0.05(0.00)$ & $<0.001$ & $-0.05(0.00)$ & $<0.001$ \\
\hline Age (after using hearing aid) & $-0.00(0.00)$ & 0.023 & $-0.01(0.00)$ & 0.014 \\
\hline Hearing aid use & $0.27(0.21)$ & 0.19 & $0.87(0.24)$ & $<0.001$ \\
\hline Female & $0.51(0.04)$ & $<0.001$ & $0.57(0.05)$ & $<0.001$ \\
\hline Married & $0.06(0.03)$ & 0.085 & $0.08(0.04)$ & 0.080 \\
\hline \multicolumn{5}{|l|}{ Education, ref: less than high } \\
\hline \multicolumn{5}{|l|}{ school } \\
\hline High school & $0.46(0.05)$ & $<0.001$ & $0.46(0.07)$ & $<0.001$ \\
\hline College or higher & $0.88(0.05)$ & $<0.001$ & $0.92(0.06)$ & $<0.001$ \\
\hline \multirow{2}{*}{\multicolumn{5}{|c|}{$\begin{array}{l}\text { Wealth, ref: } 1^{\text {st }} \text { tertile } \\
\text { (poorest) }\end{array}$}} \\
\hline & & & & \\
\hline $2^{\text {nd }}$ tertile & $0.16(0.03)$ & $<0.001$ & $0.14(0.04)$ & 0.001 \\
\hline $3^{\text {th }}$ tertile (wealthiest) & $0.26(0.04)$ & $<0.001$ & $0.28(0.05)$ & $<0.001$ \\
\hline \multicolumn{5}{|l|}{$\begin{array}{l}\text { Smoking behaviour, ref: non- } \\
\text { smoker }\end{array}$} \\
\hline Past smoker & $0.01(0.04)$ & 0.738 & $0.07(0.05)$ & 0.207 \\
\hline Current smoker & $-0.05(0.06)$ & 0.371 & $-0.00(0.07)$ & 0.988 \\
\hline Drinking regularly & $0.00(0.00)$ & 0.001 & $0.00(0.00)$ & 0.032 \\
\hline $\begin{array}{l}\text { Doing vigorous physical } \\
\text { activity }\end{array}$ & $0.06(0.02)$ & 0.015 & $0.09(0.03)$ & 0.001 \\
\hline Depression score & $-0.04(0.00)$ & $<0.001$ & $-0.05(0.00)$ & $<0.001$ \\
\hline Number of comorbidities & $-0.06(0.01)$ & $<0.001$ & $-0.05(0.01)$ & 0.002 \\
\hline
\end{tabular}


Appendix 4 Joint model predicting episodic memory scores. Source: HRS 1996-2014

\begin{tabular}{lrr}
\hline & Cofficient (SE) & P value \\
\hline Intercept & $15.62(0.26)$ & $<0.001$ \\
Age (before using hearing aid) & $-0.1(0.00)$ & $<0.001$ \\
Age (after using hearing aid) & $-0.02(0.00)$ & $<0.001$ \\
Hearing aid use & $0.68(0.31)$ & 0.031 \\
Female & $0.99(0.04)$ & $<0.001$ \\
Married & $0.05(0.06)$ & 0.42 \\
Education, ref: less than high school & & \\
High school & $0.84(0.08)$ & $<0.001$ \\
College or higher & $1.69(0.07)$ & $<0.001$ \\
Wealth, ref: $1^{\text {st }}$ tertile (poorest) & & \\
$2^{\text {nd }}$ tertile & $0.44(0.07)$ & $<0.001$ \\
$3^{\text {th }}$ tertile (wealthiest) & $0.7(0.07)$ & $<0.001$ \\
Smoking behaviour, ref: non-smoker & & \\
Past smoker & $-0.01(0.6)$ & 0.81 \\
Current smoker & $-0.06(0.1)$ & 0.51 \\
Drinking regularly & $0.47(0.09)$ & 0.009 \\
Doing vigorous physical activity & $0.18(0.05)$ & $<0.001$ \\
Depression score & $-0.14(0.01)$ & $<0.001$ \\
Number of comorbidities & $-0.1(0.02)$ & $<0.001$ \\
\hline
\end{tabular}


Appendix 6 Hearing aid use and episodic memory scores by gender, coefficients and standard errors. Source: HRS 1996-2014.

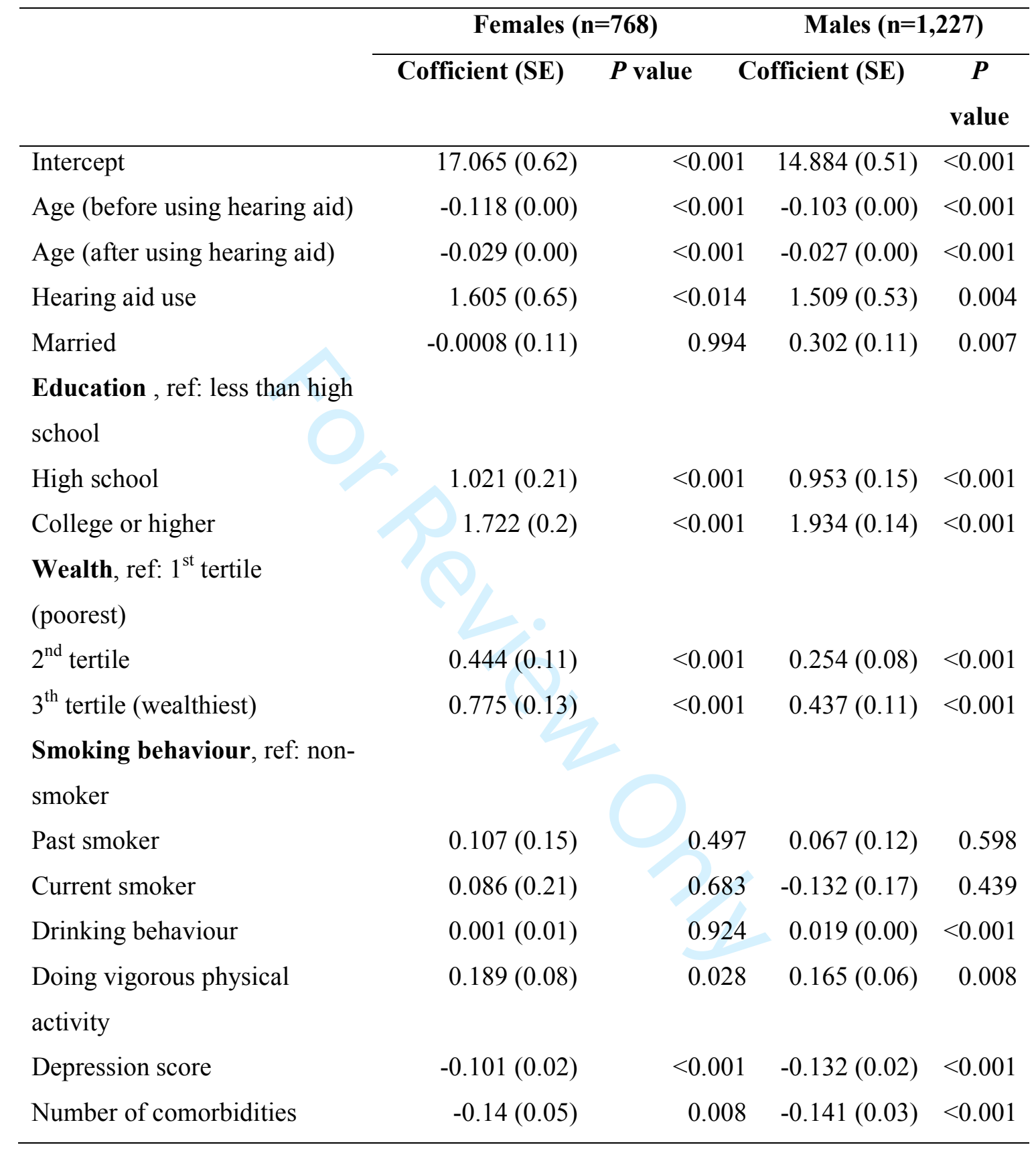


Appendix 8 The comparison of letter cancellation performance between respondents with different sensory function. Source: ELSA Wave 5 (2010).

\begin{tabular}{lrrr}
\hline & N & Mean & \multicolumn{2}{c}{$\begin{array}{c}\text { Standard } \\
\text { deviation }\end{array}$} \\
\hline All sample & 10,274 & 18.91 & 5.4 \\
No hearing impairment & 8,121 & 19.22 & 5.44 \\
Hearing impairment & 2,142 & 17.66 & 5.3 \\
p-value* & $<0.001$ & & \\
& & & 5.3 \\
No visual impairment & 8,881 & 19.16 & 5.8 \\
Visual impairment & 1,381 & 17.03 & \\
p-value* & $<0.001$ & & \\
\hline
\end{tabular}

Note: *: calculated using chi-square tests. 
Page 65 of 67

Journal of the American Geriatrics Society

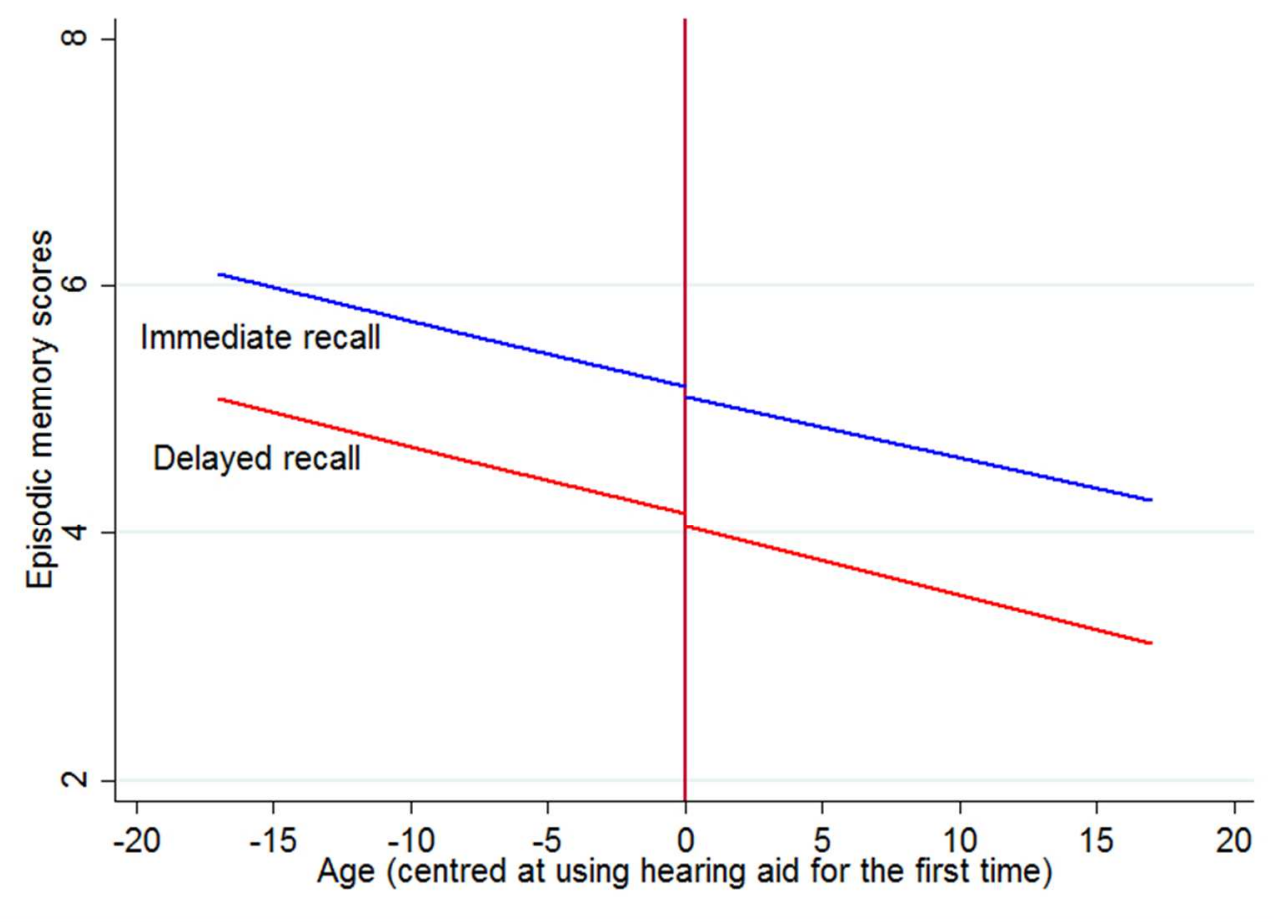

$276 \times 201 \mathrm{~mm}(72 \times 72$ DPI $)$ 


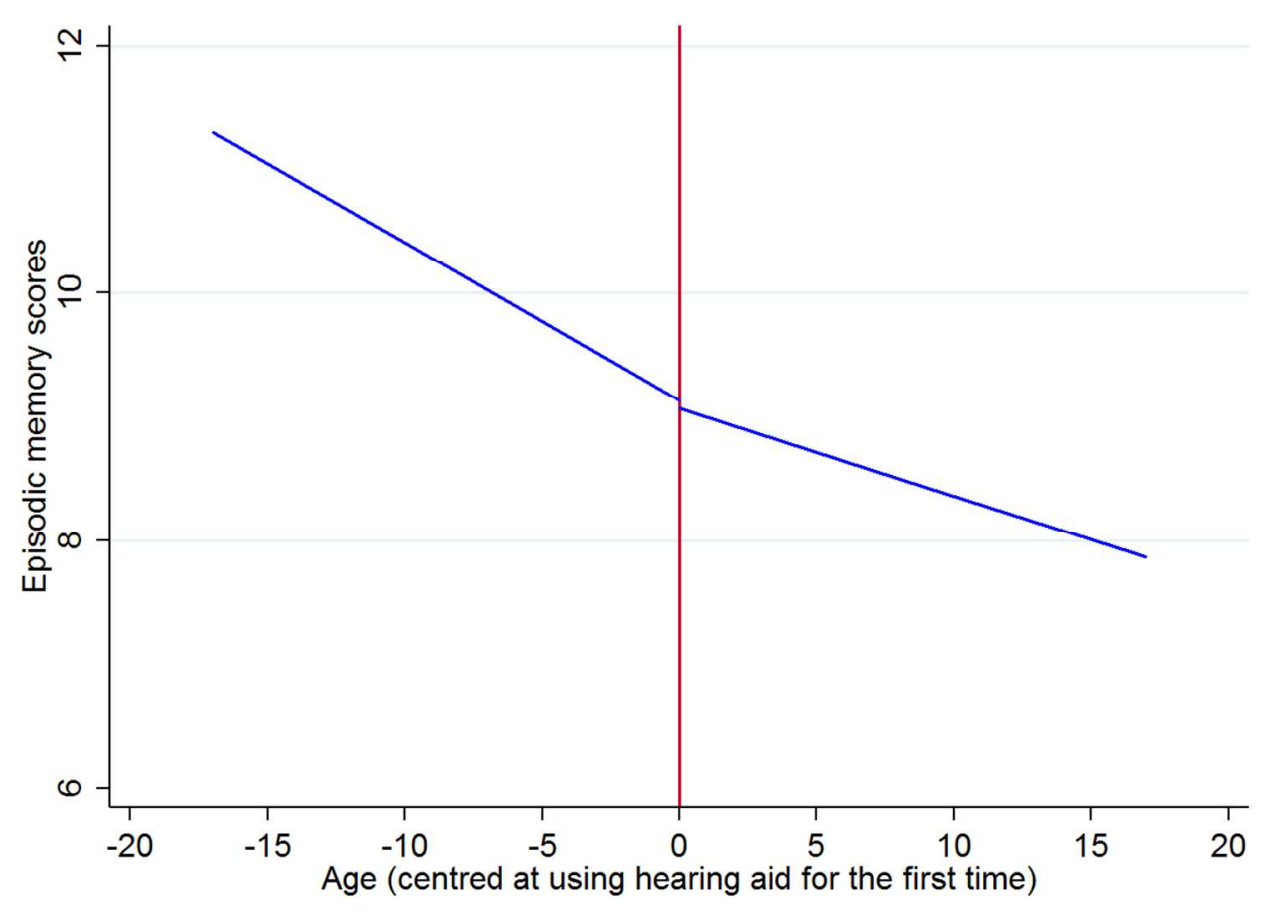

$453 \times 329 \mathrm{~mm}(72 \times 72 \mathrm{DPI})$ 
Page 67 of 67

Journal of the American Geriatrics Society

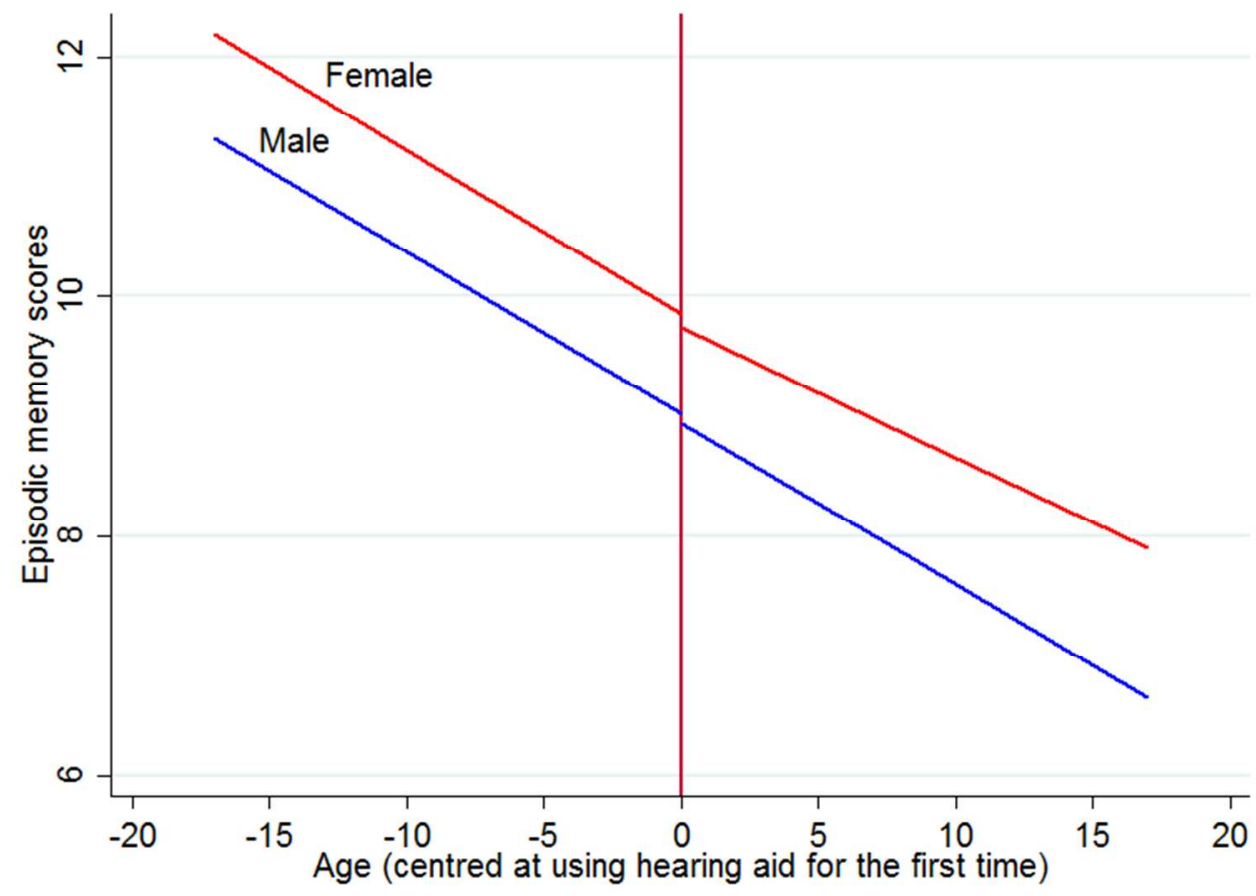

$276 \times 201 \mathrm{~mm}(72 \times 72$ DPI $)$ 